\title{
BMJ Open Diabetes, hypertension, body mass index, smoking and COVID-19-related mortality: a systematic review and meta- analysis of observational studies
}

\author{
Yahya Mahamat-Saleh (D) , ${ }^{1}$ Thibault Fiolet, ${ }^{1}$ Mathieu Edouard Rebeaud, ${ }^{2}$ \\ Matthieu Mulot, ${ }^{3}$ Anthony Guihur (D) , ${ }^{2}$ Douae El Fatouhi, ${ }^{1}$ Nasser Laouali, ${ }^{1}$ \\ Nathan Peiffer-Smadja, ${ }^{4,5,6}$ Dagfinn Aune (1) , ${ }^{7,8,9,10}$ Gianluca Severi ${ }^{1,11}$
}

To cite: Mahamat-Saleh Y, Fiolet T, Rebeaud ME, et al. Diabetes, hypertension, body mass index, smoking and COVID-19-related mortality: a systematic review and meta-analysis of observational studies. BMJ Open 2021;11:e052777. doi:10.1136/ bmjopen-2021-052777

- Prepublication history and additional supplemental material for this paper are available online. To view these files, please visit the journal online (http://dx.doi.org/10.1136/ bmjopen-2021-052777).

DA and GS are joint senior authors.

Received 26 April 2021 Accepted 07 October 2021

\section{Check for updates}

(c) Author(s) (or their employer(s)) 2021. Re-use permitted under CC BY-NC. No commercial re-use. See rights and permissions. Published by BMJ.

For numbered affiliations see end of article.

\section{Correspondence to} Dr Yahya Mahamat-Saleh; Yahya.MAHAMAT-SALEH@ gustaveroussy.fr

\section{ABSTRACT}

Objectives We conducted a systematic literature review and meta-analysis of observational studies to investigate the association between diabetes, hypertension, body mass index (BMI) or smoking with the risk of death in patients with COVID-19 and to estimate the proportion of deaths attributable to these conditions.

Methods Relevant observational studies were identified by searches in the PubMed, Cochrane library and Embase databases through 14 November 2020. Randomeffects models were used to estimate summary relative risks (SRRs) and 95\% Cls. Certainty of evidence was assessed using the Cochrane methods and the Grading of Recommendations, Assessment, Development and Evaluations framework.

Results A total of 186 studies representing 210447 deaths among 1304587 patients with COVID-19 were included in this analysis. The SRR for death in patients with COVID-19 was 1.54 (95\% Cl 1.44 to $1.64, I^{2}=92 \%, n=145$, low certainty) for diabetes and 1.42 (95\% $\mathrm{Cl} 1.30$ to 1.54 , $\mathrm{I}^{2}=90 \%, \mathrm{n}=127$, low certainty) for hypertension compared with patients without each of these comorbidities. Regarding obesity, the SSR was 1.45 (95\% Cl 1.31 to $1.61, I^{2}=91 \%, n=54$, high certainty) for patients with $\mathrm{BMI} \geq 30 \mathrm{~kg} / \mathrm{m}^{2}$ compared with those with $\mathrm{BMl}<30 \mathrm{~kg} /$ $\mathrm{m}^{2}$ and $1.12\left(95 \% \mathrm{Cl} 1.07\right.$ to $\left.1.17, \mathrm{I}^{2}=68 \%, \mathrm{n}=25\right)$ per 5 $\mathrm{kg} / \mathrm{m}^{2}$ increase in BMI. There was evidence of a J-shaped non-linear dose-response relationship between BMI and mortality from COVID-19, with the nadir of the curve at a BMI of around 22-24, and a 1.5-2-fold increase in COVID-19 mortality with extreme obesity (BMI of 40-45). The SRR was 1.28 (95\% Cl 1.17 to $1.40, I^{2}=74 \%, n=28$, low certainty) for ever, 1.29 (95\% Cl 1.03 to $1.62, l^{2}=84 \%$, $\mathrm{n}=19)$ for current and $1.25\left(95 \% \mathrm{Cl} 1.11\right.$ to $1.42, \mathrm{I}^{2}=75 \%$, $\mathrm{n}=14$ ) for former smokers compared with never smokers. The absolute risk of COVID-19 death was increased by $14 \%, 11 \%, 12 \%$ and $7 \%$ for diabetes, hypertension, obesity and smoking, respectively. The proportion of deaths attributable to diabetes, hypertension, obesity and smoking was $8 \%, 7 \%, 11 \%$ and $2 \%$, respectively.

Conclusion Our findings suggest that diabetes, hypertension, obesity and smoking were associated with higher COVID-19 mortality, contributing to nearly $30 \%$ of COVID-19 deaths.

Trial registration number CRD42020218115.

\section{Strengths and limitations of this study}

- We did a systematic review and meta-analysis of 186 observational studies (210 447 deaths among 1 304587 patients with COVID-19) to investigate the association between diabetes, hypertension, obesity and smoking and risk of death in patients with COVID-19 and to estimate the proportion of deaths attributable to these four conditions.

- We performed several subgroup analyses, and assessed certainty of evidence using the Cochrane methods and the Grading of Recommendations, Assessment, Development and Evaluations framework. A non-linear dose-response relation between body mass index and COVID-19 mortality was also explored.

- However, we did not investigate the association between presence of two or more coexisting comorbidities and risk of death in patients with COVID-19.

\section{INTRODUCTION}

COVID-19 is a viral infectious disease caused by SARS-CoV-2, which was first reported in Wuhan City, China, in December 2019. ${ }^{1}$ SARS-CoV-2 has since spread to all countries worldwide and COVID-19 has been declared a pandemic by the WHO. ${ }^{2}$ As of 24 August 2021, over 212.3 million cases and 4.4 million deaths have been reported globally since the start of the pandemic. ${ }^{3}$ Age is the main risk factor for poor outcome in people with COVID-19 infection, ${ }^{45}$ as it is correlated with more comorbidities. About $70 \%-87 \%$ of COVID-19 deaths are among people aged 70 years or older. ${ }^{6}$ Patients with comorbidities, including diabetes, cardiovascular disease, respiratory disease, chronic kidney disease and others chronic diseases are at increased risk of developing severe or critical COVID$19,{ }^{8}{ }^{9}$ which may partly explain a greater mortality in hospital. ${ }^{10-14}$ Studies suggest that 
about $20 \%-51 \%$ of patients hospitalised with COVID-19 have at least one comorbidity. ${ }^{1015}$

Previous meta-analyses reported a higher mortality rate from COVID-19 in patients with comorbidities. ${ }^{16-22}$ Ssentongo et al, based on 25 studies published from December 2019 to 9 July 2020, suggested that diabetes and hypertension were respectively associated with a 1.48 -fold and 1.82-fold greater risk of COVID-19 death compared with those without these comorbidities. ${ }^{16}$ Based on studies published during the same period, Luo et al reported similar results. ${ }^{17} \mathrm{Du}$ et al found that patients with obesity had a 2.68-fold risk of dying from COVID-19 compared with non-obese patients. ${ }^{18}$ Most of the published metaanalyses did not investigate the shape of the dose-response relationship between body mass index (BMI) and risk of death in order to clarify whether the association is dosedependent or if there are threshold effects. ${ }^{20}{ }^{23-25}$ In addition, evidence suggests that smoking may increase risk of severe disease and death from COVID-19. ${ }^{19}$ However, it is not clear whether such an increase in COVID-19 mortality is different in current and past smokers since previous meta-analyses have not performed separate analyses. ${ }^{19} 2627$

However, since the publication of these meta-analyses, several observational studies have been published on diabetes, hypertension, obesity or smoking and risk of death in patients with COVID-19 ${ }^{48-122}$ and the strength of the associations differed greatly between studies. Moreover, the proportion of deaths attributable to diabetes, hypertension, obesity or smoking habits has not been estimated. This last aspect may help adapting public health measures and vaccination strategies to populations at risk of severe COVID-19.

Given the rapidly increasing death from COVID-19 globally, and since diabetes, hypertension, obesity and tobacco smoking represent the most important public health problems worldwide, which contributed to higher risk of death globally; we thus conducted a systematic review and meta-analysis of published observational studies to investigate the association between diabetes, hypertension, smoking and obesity and risk of death in patient with COVID-19 and to clarify the strength of these associations. We further estimated the proportion of deaths attributable to these conditions.

\section{MATERIALS AND METHODS}

\section{Search strategy and selection criteria}

The meta-analysis was reported according to the Preferred Reporting Items for Systematic Reviews and MetaAnalyses statement ${ }^{123}$ and Meta-Analysis of Observational Studies in Epidemiology. ${ }^{124}$ This study was registered and accepted in the International Prospective Register of PROSPERO in October 2020. PubMed (MEDLINE), Cochrane library and Embase databases were searched to identify relevant articles published in English from December 2019 to 14 November 2020. The search terms that we used are provided in online supplemental file.
In addition, we searched the reference lists of the relevant publications, reviews and meta-analyses to identify additional potentially relevant studies. We only included observational studies (cohort studies and cross-sectional) that reported relative risk estimates (such as hazard ratios (HRs), relative risk (RR) or odds ratios (ORs)) with the $95 \%$ CIs with or without adjustment for potential confounders. The search was independently screened by two researchers (YM-S and TF) and discrepancies were resolved by discussion with a third researcher (MER).

\section{Data collection}

From each included publication, we extracted results and study characteristics which included first author's last name, publication year, country where the research was conducted in, study design, study description or name, study period, sample size with number of deaths, exposure, categories, risk estimate and 95\% CIs, and adjustment factors. Data were extracted by YM-S and extractions were checked for accuracy by TF. Discrepancies were resolved through discussion with a third researcher (MER).

\section{Quality assessment and risk of bias}

The quality of individual studies was assessed independently by two researchers (YM-S and TF) using the Cochrane risk of bias tool ROBINS-I, which grades studies on a scale from critical risk of bias to low risk of bias considering bias due to confounding, selection of study participants, exposure measurement, misclassification of exposure during follow-up, missing data, measurement of outcomes and bias due to selection of reported results. ${ }^{125}$ Following the assessment of risk of bias, the body of evidence for each comorbidity and risk of death was rated independently using the Grading of Recommendations, Assessment, Development and Evaluations approach. ${ }^{126}$ Discrepancies were resolved through discussion with a third researcher (DA).

\section{Data analysis}

We used random effects models that consider both within study and between-study variation to calculate summary RRs (SRRs) (95\% CIs) of COVID-19 mortality for patients with diabetes compared with those without diabetes, for patients with hypertension versus those without hypertension, for obese versus non-obese and for current, former and ever smoker compared with never smokers. The natural logarithm of the RRs was weighted using random effects weights. ${ }^{127}$ Statistical heterogeneity between studies was assessed by the Cochrane $\mathrm{Q}$ test and the $\mathrm{I}^{2}$ statistic. ${ }^{128}$ We calculated the absolute risk difference (RD) from the baseline risk of mortality (BR) from Docherty et al, ${ }^{129}$ large cohort and relative risk (RR) using the formula $\mathrm{RD}=\mathrm{BR} \times(\mathrm{RR}-1) .{ }^{130}$

We further performed a dose-response analysis for the associations between BMI and COVID-19 mortality using the method described by Greenland and Longnecker to compute the linear trend from the natural logs of the RRs and CIs across categories of BMI. ${ }^{131}$ We calculated SRRs 
and $95 \%$ CIs for a 5-unit increment in BMI using random effects models. This method required mean or median of BMI, RRs and 95\% CIs for at least three categories. The mean or median BMI level per category was used if provided in the publication, and if not, the midpoint of the upper and lower boundaries was estimated as a range in each category. When the highest and lowest categories were open-ended, we used the width of the adjacent interval to estimate the upper and lower boundaries for the category. For studies that reported results separately for young and adults, for current and former smoker, but not overall, we pooled the results using a fixed-effects model as reported by the Hamling procedure to obtain an overall estimate to be used in the meta-analysis. ${ }^{132}$

To explore the potential non-linear dose-response relation between BMI and mortality among patients with COVID-19, we used fractional polynomial models. ${ }^{133}$ We determined the best fitting second order fractional polynomial regression model, defined as the one with the lowest deviance. Only studies which presented more than two categories of BMI were included in the non-linear analysis. Subgroup and meta-regression analyses were conducted to investigate potential sources of heterogeneity. Small-study effects, such as publication bias, were visually assessed by examining funnel plots for asymmetry, and with Egger's test, ${ }^{134}$ and the results were considered to indicate potential small-study bias when $\mathrm{p}$ values were $<0.10$. We conducted sensitivity analyses excluding one study at a time to clarify whether the results were driven by one large study or a study with an extreme result.

We finally calculated the population attributable fraction (PAF) of mortality among patients with COVID-19 due to diabetes, hypertension, obesity and smoking, worldwide using the following formula ${ }^{135}$ :

$$
\mathrm{PAF}=\frac{\mathrm{p} \times(\mathrm{RR}-1)}{[\mathrm{p} \times(\mathrm{RR}-1)+1]}
$$

Where RR was the relative risk, $p$ was the prevalence of the exposure in patient with COVID-19. The prevalence of diabetes $(11.5 \%)$, hypertension $(22.9 \%)$, obesity $(29 \%)$ and smoking $(9 \%)$ were obtained from previous meta-analyses. ${ }^{136-138}$

\section{Patient and public involvement}

Patients or the public were not involved in any aspect of the study design, conduct or in the development of the research question or outcome measures.

\section{RESULTS}

A total of 6007 records were identified in MEDLINE, Cochrane library and in EMBASE (figure 1). A total of 4665 publications were excluded after reading title and abstract or because of duplicates. Among 1342 full-text articles retrieved, 994 were excluded as not meeting the inclusion criteria, leaving a total of 348 publications. Of these, 162 articles were not eligible because they lacked sufficient data, ${ }^{139} 140$ reported no risk estimate or

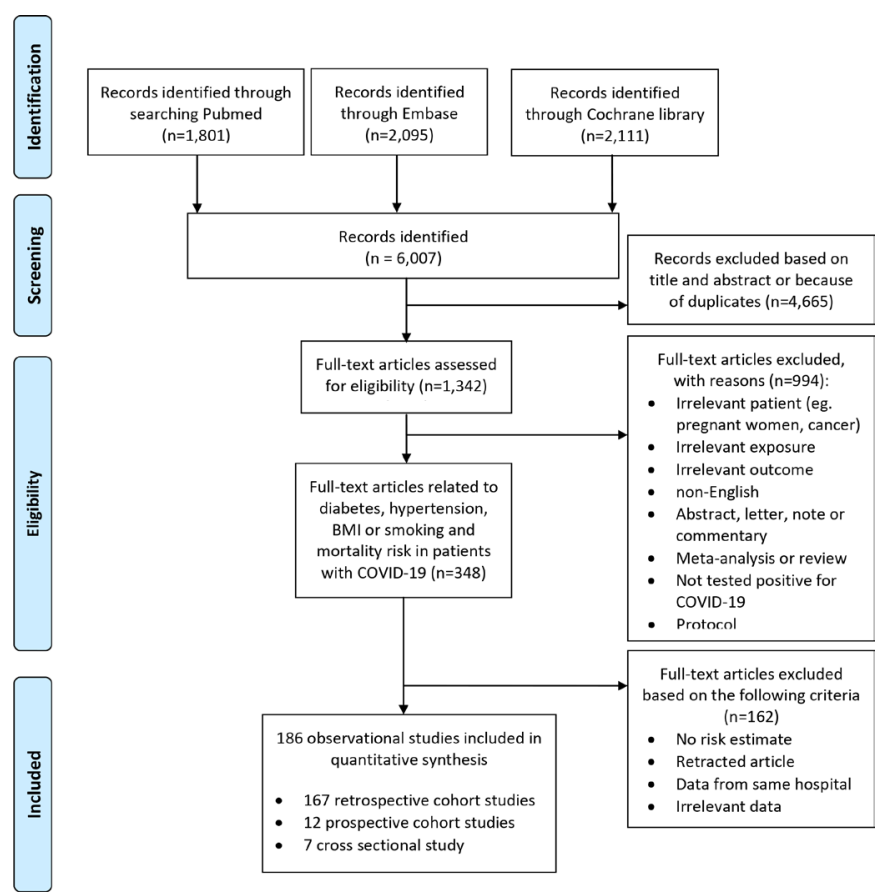

Figure 1 Flow-chart of study selection.

irrelevant data, ${ }^{139} 140$ because they had identical populations ${ }^{141-151}$ or were retracted. ${ }^{152}$ Finally, a total of 186 observational studies were included in this meta-analysis. Of the included studies, 58 were from Europe, 58 from North America, 60 from Asia, 6 from South America and 4 from Africa (online supplemental table 1). From the 186 publications assessed using the ROBINS-I tool, 92 were evaluated as being at low risk of bias, 49 at moderate risk of bias, 21 at serious risk of bias and 24 at critical risk of bias because of insufficient adjustment of relevant confounders (online supplemental table 2).

\section{Diabetes and mortality in patient with COVID-19}

A total of 145 studies ${ }^{48-119} 121122129$ 153-201 were included in the analysis of the association between diabetes and mortality, including a total of 198491 deaths among 1 165897 patients with COVID-19. The SRR for diabetes patients compared with those without diabetes was 1.54 (95\% CI 1.44 to 1.64$)$ and there was high heterogeneity among studies $\left(\mathrm{I}^{2}=92 \%\right)$. We found that diabetes increased the absolute risk of death by $14 \%$ (table 1 ). The funnel plot did not provide evidence of publication bias (online supplemental figure 1) and we found no evidence of small study effects (Egger's test, $p$ value $=0.54$ ).

The positive association persisted across all subgroups analyses stratified by study design, number of patients, geographic location and adjustment for some confounding factors (table 2). However, metaregression analyses suggested some indication of heterogeneity between studies that adjusted for multiple factors such as age, sex and other comorbidities versus studies without such adjustment or adjusted for age only ( $\mathrm{P}_{\mathrm{h}}$ neity $=0.003$ ), with a stronger association for the studies with no adjustment factors or those adjusted for age only. The 


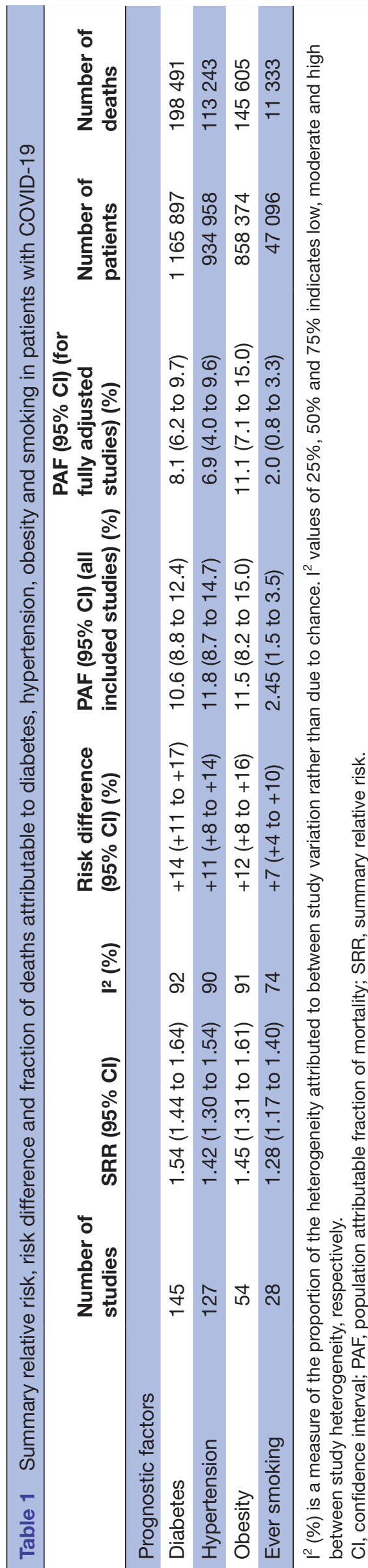

positive association was also stronger among studies with critical or serious risk of bias compared with those with moderate or low risk of bias, with heterogeneity detected across studies $\left(\mathrm{P}_{\text {heterogeneity }}=0.001\right)$.

The influence analysis showed no substantial influence of any of the included studies on the global estimate of diabetes and mortality. The SRR ranged from $1.51(95 \%$ CI 1.42 to 1.61 ) when excluding the Barbu et al study ${ }^{35}$ to 1.55 (95\% CI 1.45 to 1.64 ) when excluding the Meng et al study $^{114}$ (online supplemental figure 2 ).

\section{Hypertension and mortality in patient with COVID-19}

We included 127 observational studies 4293032 33 35-40 42-45 47-50 52-56 $585961-63656669$ 71-76 78 81-84 86 88-90 92-95 97103105106 108-112 114-118 120-122 153154 156-159 161-167 169 173-180 182-188 193-200 ${ }^{202-219}$ in the analysis of the association between hypertension and mortality, including a total of 113243 deaths among 934958 patients with COVID-19. The SRR for hypertension patients versus those without hypertension was 1.42 (95\% CI 1.30 to 1.54$)$ with high evidence of heterogeneity $\left(I^{2}=90 \%\right)$ (table 1$)$. The absolute risk of death for patients with COVID-19 with hypertension compared with without hypertension was increased by $11 \%$. Small study effects, such as publication bias, were not indicated with the funnel plot (online supplemental figure 3) or Egger's test ( $p$ value $=0.26$ ).

Here again, the positive association persisted in most subgroup analyses (table 2). Our meta-regression analysis showed that the study design and the geographic location did not significantly influence the magnitude of the overall association. However, heterogeneity between subgroup analyses was observed in analyses stratified by risk of bias with higher association for studies with critical compared with those with low, moderate or serious risk of bias $\left(\mathrm{P}_{\text {heterogeneity }} \leq 0.0001\right)$ and by adjustment for confounding factors with higher association for studies without adjustment compared with those that adjusted for age only or for multiple factors $\left(\mathrm{P}_{\text {heterogeneity }} \leq 0.0001\right)$.

When excluding the most influential studies, we found no substantial influence of any of the included studies (online supplemental figure 4).

\section{BMI and mortality in patient with COVID-19}

Fifty-four studies $293238444548495261626465676973747984-86$ 88-90 9399103107118 120-122 129154164165178181182184192196197202 206 220-228 investigated BMI and mortality risk including 145605 deaths among 858374 patients with COVID-19 were identified. The analysis yielded an SRR of $1.45(95 \%$ CI 1.31 to 1.61 ) for obese (BMI $\geq 30 \mathrm{~kg} / \mathrm{m}^{2}$ ) versus nonobese $\left(\mathrm{BMI}<30 \mathrm{~kg} / \mathrm{m}^{2}\right)$ patients, with high heterogeneity detected between studies $\left(I^{2}=91 \%\right)$ (figure 2) (table 1 ). We found that obesity increased the absolute risk of death by $12 \%$. There was no statistically significant evidence of publication bias ( $p$ value Egger's test=0.92) (online supplemental figure 5). The meta-regression analysis showed that study characteristics did not significantly alter the overall estimate (online supplemental table 3). When excluding the most influential studies one by one, 
Table 2 Subgroup analyses of association between diabetes and hypertension and mortality risk in patients with COVID-19

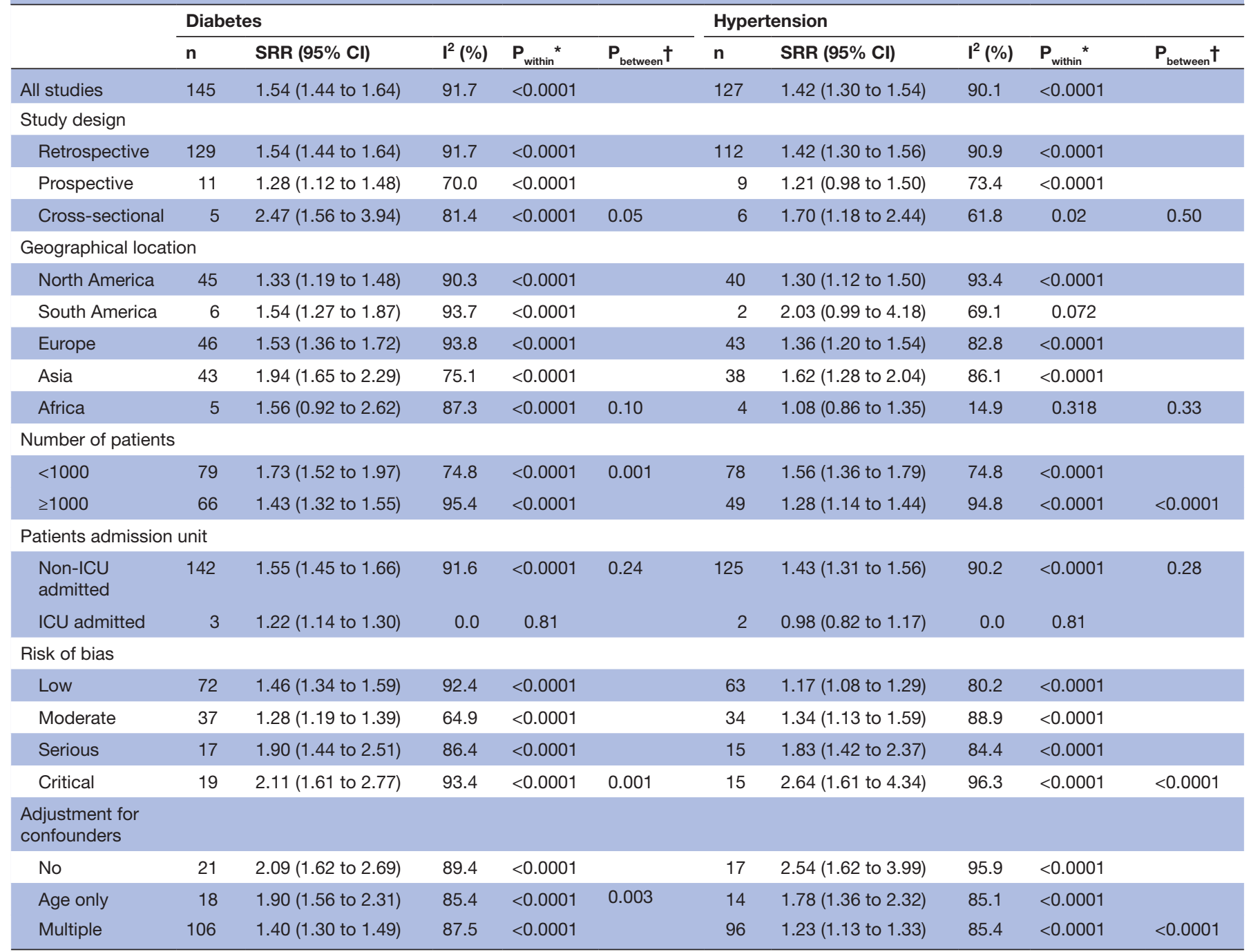

$\mathrm{I}^{2}(\%)$ is a measure of the proportion of the heterogeneity attributed to between study variation rather than due to chance. $\mathrm{I}^{2}$ values of $25 \%, 50 \%$ and $75 \%$ indicates low, moderate and high between study heterogeneity, respectively.

${ }^{*} P$ value for heterogeneity within each subgroup.

TP value for heterogeneity between subgroups with meta-regression analysis.

$\mathrm{Cl}$, confidence interval; ICU, intensive care unit; SRR, summary relative risk.

the global estimate did not substantially change (online supplemental figure 6).

Twenty-five $\quad$ studies $\quad(32 \quad 072 \quad$ deaths among $95 \quad 852$ patients with COVID19) $38566174868991-9397108111112161162175177221222$ 229-235 were included in the dose-response meta-analysis of BMI and mortality risk. The summary RR for a $5 \mathrm{~kg} / \mathrm{m}^{2}$ increment in BMI was 1.12 (95\% CI 1.07 to $1.17, \mathrm{I}^{2}=68 \%$ ) (figure 3) and no statistically significant evidence of publication bias ( $\mathrm{p}$ value $=0.11$ ) or by inspection of the funnel plot was observed (online supplemental figure 7). However, evidence of a J-shaped non-linear relation between BMI and mortality risk was observed $\left(\mathrm{P}_{\text {non-linearity }} \leq 0.0001\right)$, suggesting a flat dose-response curve at a BMI around $22-24 \mathrm{~kg} / \mathrm{m}^{2}$ with a slight increase in risk of death below that range and a 1.5-2-fold increase in risk of death with a BMI of $40-45$ versus $22-24 \mathrm{~kg} / \mathrm{m}^{2}$ (figure 4 ).
In sensitivity analyses excluding one study at a time from the analysis, the summary for a $5 \mathrm{~kg} / \mathrm{m}^{2}$ increment in BMI ranged from 1.11 (95\% CI 1.06 to 1.15 ) when excluding the Czernichow et al. Study ${ }^{108}$ to $1.13(95 \%$ CI 1.08 to 1.19 ) when excluding the Ferrando-Vivas et al $\operatorname{study}^{230}$ (online supplemental figure 8).

\section{Smoking and mortality in patient with COVID-19}

Twenty-eight studies ${ }^{38} 405861636667769397103108110111118121$ 129161 164-166 175177183232 236-238 were included in the analysis of ever smoking versus never smoking and mortality with a total of 11333 deaths among 47096 patients with COVID-19. The SRR for hospital death in patient with COVID-19 was 1.28 (95\% CI 1.17 to $1.40, \mathrm{I}^{2}=74 \%$ ) for ever smokers versus never smokers (figure 5). The absolute risk of death for smoking was increased by $7 \%$ (table 1 ). There was no evidence of publication or small study bias 


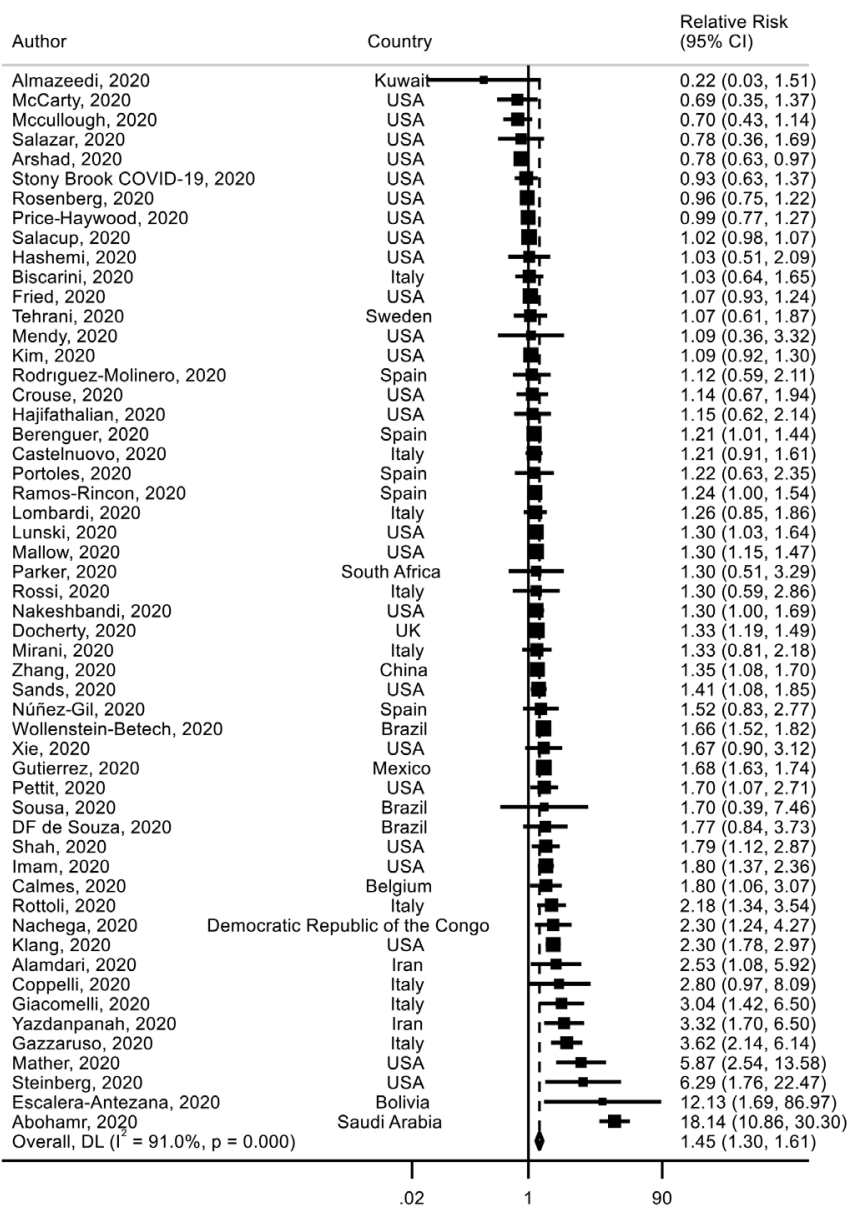

Figure 2 Association between obesity and mortality risk in patients with COVID-19.

( $p$ value $=0.91)$ (online supplemental figure 9). In sensitivity analyses, the results persisted when excluding one study at a time (online supplemental figure 10).

For current smoking versus never smoking, nineteen studies, ${ }^{4} 58667697103110111117118121129161162165177203236239$ which included 9845 deaths among 33147 patients with COVID-19, were identified. The SRR of current smoking was 1.29 (95\% CI 1.03 to $1.62, \mathrm{I}^{2}=84 \%$ ) (figure 6) and no statistically significant evidence of publication bias was observed ( $\mathrm{p}$ value $=0.86$ ) (online supplemental figure 11).

A total of 14 studies 58667697103110111118121129161165177236 were included in the analysis of former smoking versus never smoking and mortality risk, including 8121 deaths among 25340 patients with COVID-19. The SRR was 1.25 (95\% CI 1.11 to 1.42 ) with moderate to high heterogeneity $\left(\mathrm{I}^{2}=75 \%\right)$ (figure 7$)$. There was no evidence of publication bias with Egger's test ( $p$ value $=0.70$ ). In sensitivity analyses excluding one study at a time from the analyses of current and former smoking, the results were not materially altered (online supplemental figures 12-13). Globally, results did not change in nearly all subgroup analyses (online supplemental table 4).

Finally, a total of 15 studies ${ }^{29445258107174186192208218240-243}$ did not provide a definition of the smoking variable $(>76$ 400 deaths, 682310 patients) and the SRR was 1.31 (95\%

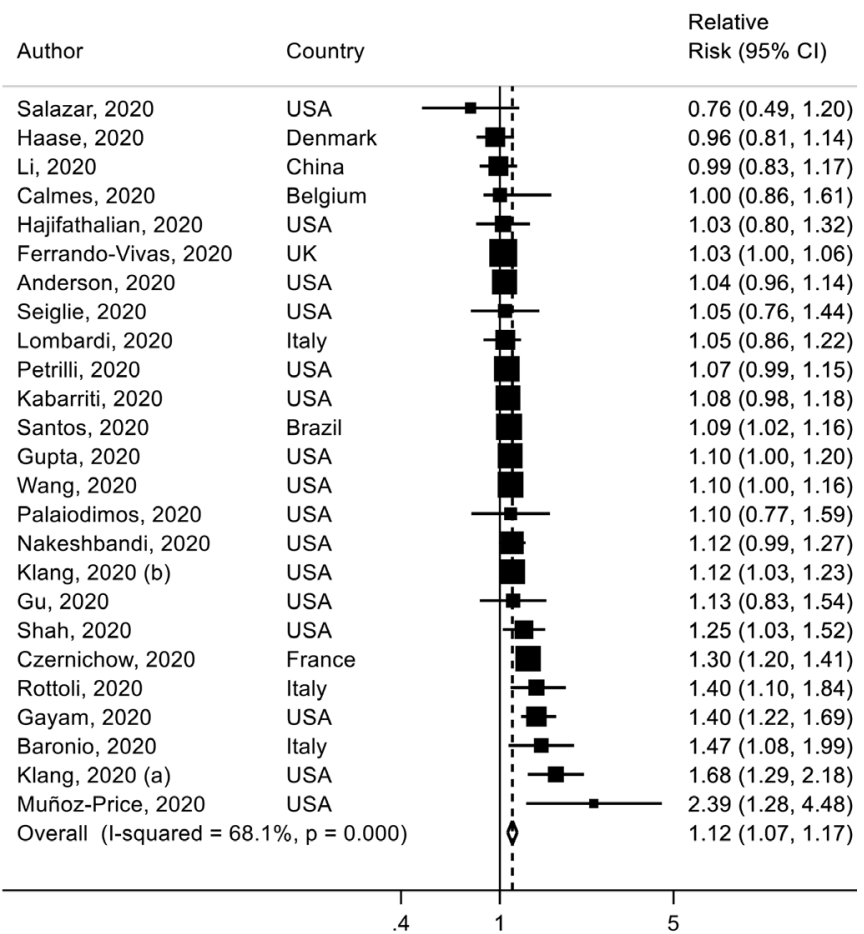

Figure 3 Association between body mass index (BMI) and mortality risk in patients with COVID-19, linear doseresponse analysis, per $5 \mathrm{~kg} / \mathrm{m}^{2}$ increment of BMI.

CI 1.07 to $1.62, \mathrm{I}^{2}=88 \%$ ) (online supplemental figure 14 ) which seemed to be similar to current and ever smoking.

\section{PAF of deaths and assessment of certainty of the body of evidence}

The estimated PAF was $10.6 \%, 11.8 \%, 11.5 \%$ and $2.5 \%$ for diabetes, hypertension, obesity and ever smoking, respectively when considering all studies included in this meta-analysis (table 1). Based on studies that adjusted for multiple risk factors, attributable death was $8 \%$ for

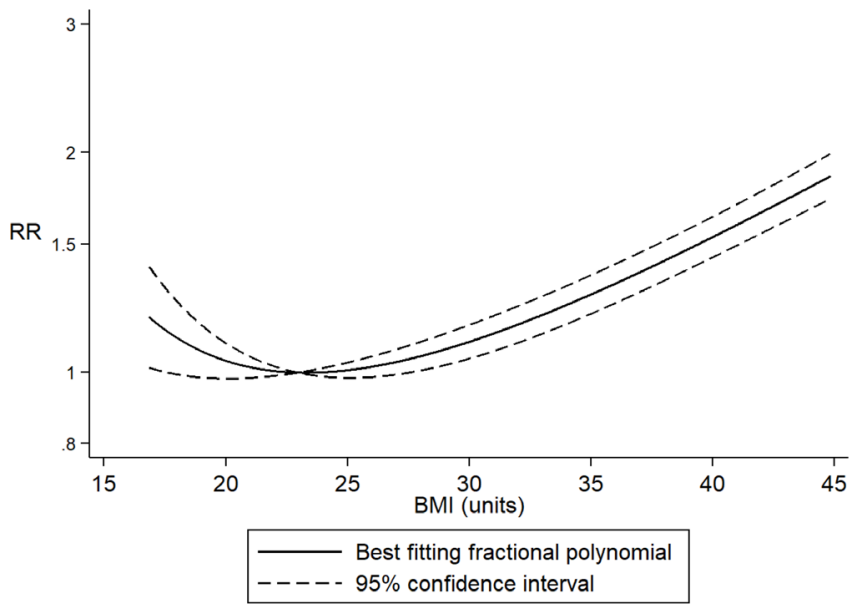

Figure 4 Association between body mass index (BMI) and mortality risk in patients with COVID-19: non-linear doseresponse analysis. 


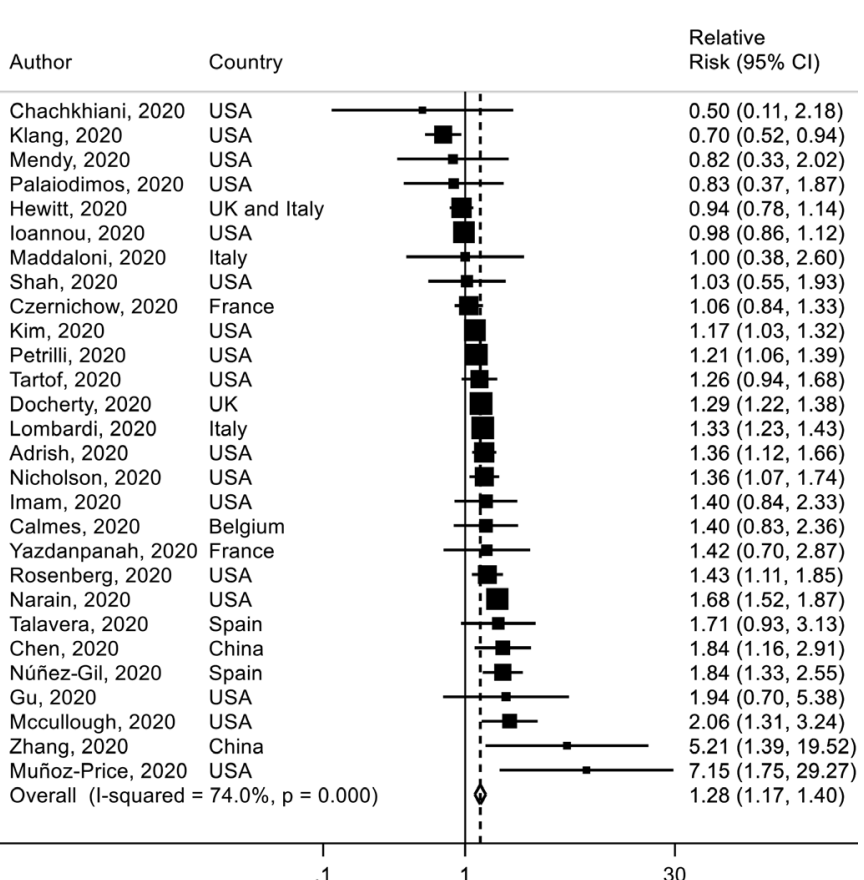

Figure 5 Association between ever smoking (vs never smoking) and mortality risk in patients with COVID-19.

diabetes, $7 \%$ for hypertension, $11 \%$ for obesity and $2 \%$ for ever smoking.

Regarding the body of evidence, certainty of evidence was rated 'low' for diabetes, hypertension and smoking and 'high' for obesity (online supplemental table 5).

\section{DISCUSSION}

\section{Principal findings}

To our knowledge, this study is one of the largest metaanalyses of association between diabetes, hypertension, obesity, smoking and COVID-19 mortality. We found that

\begin{tabular}{|c|c|c|}
\hline Author & Country & $\begin{array}{l}\text { Relative } \\
\text { Risk (95\% Cl) }\end{array}$ \\
\hline Mccullough, 2020 & USA & $0.33(0.04,2.56)$ \\
\hline Tartof, 2020 & USA & $0.84(0.30,2.35)$ \\
\hline Ioannou, 2020 & USA & $0.87(0.67,1.13)$ \\
\hline Hewitt, 2020 & UK and Italy & $0.91(0.59,1.41)$ \\
\hline Petrilli, 2020 & USA & $0.92(0.62,1.37)$ \\
\hline Castelnuovo, 2020 & Italy & $0.94(0.69,1.28)$ \\
\hline Nicholson, 2020 & USA & $1.06(0.78,1.44)$ \\
\hline Docherty, 2020 & UK & $1.09(0.95,1.26)$ \\
\hline Gupta, 2020 & USA & $1.21(0.76,1.93)$ \\
\hline Kim, 2020 & USA & $1.22(0.99,1.51)$ \\
\hline Rosenberg, 2020 & USA & $1.30(0.74,2.29)$ \\
\hline Yazdanpanah, 2020 & France & $1.36(0.31,5.91)$ \\
\hline Narain, 2020 & USA & $1.43(0.93,2.19)$ \\
\hline Adrish, 2020 & USA & $1.62(1.23,2.14)$ \\
\hline Núñez-Gil, 2020 & Spain & $1.95(0.90,4.21)$ \\
\hline Zhou, 2020 & China & $2.23(0.65,7.64)$ \\
\hline Gu, 2020 & USA & $2.40(0.15,39.00)$ \\
\hline Alharthy, 2020 & Saudi Arabia & $3.00(2.48,3.62)$ \\
\hline Nie, 2020 & China & $3.66(1.41,9.48)$ \\
\hline \multicolumn{2}{|c|}{ Overall $(I-$ squared $=84.2 \%, p=0.000)$} & $1.29(1.03,1.62)$ \\
\hline & .01 & \\
\hline
\end{tabular}

Figure 6 Association between current smoking (vs never smoking) and mortality risk in patients with COVID-19.

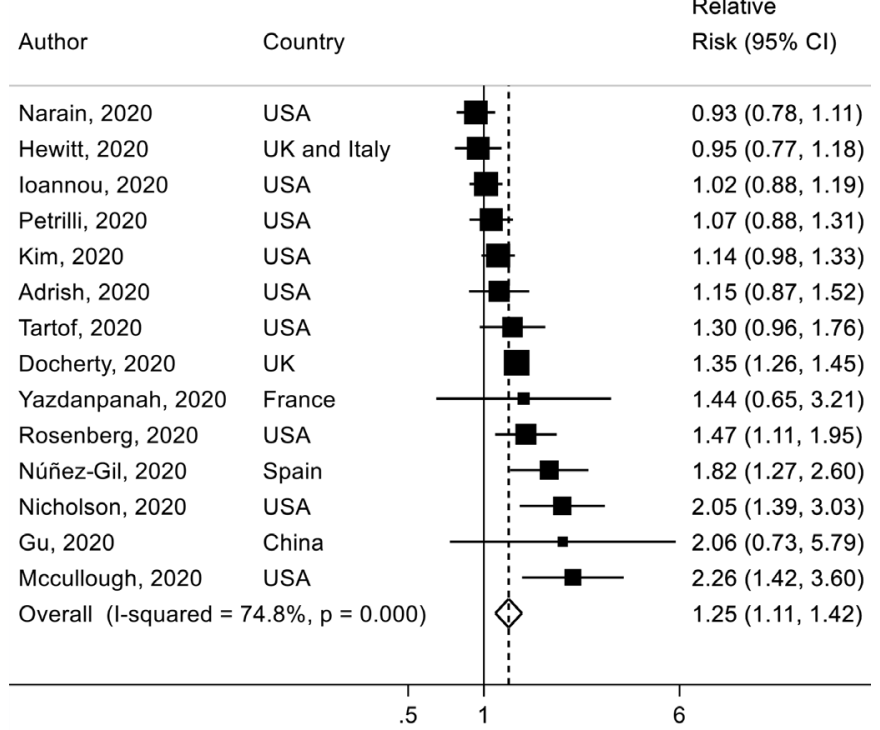

Figure 7 Association between former smoking (vs never smoking) and mortality risk in patients with COVID-19.

patients with diabetes had a 54\% higher risk of death from COVID-19 compared with patients without diabetes; those with hypertension had a $42 \%$ increase in the relative risk of death from COVID-19 compared with patients without hypertension and those with obesity have a $45 \%$ greater in the relative risk of COVID-19 death compared with non-obese patients. In addition, we found that ever, current and former smoking was associated with $28 \%$, $29 \%$ and $25 \%$ increases in the relative risk of death in patients with COVID-19. Our linear dose-response metaanalysis suggested that each $5 \mathrm{~kg} / \mathrm{km}^{2}$ increment in BMI was associated with a $12 \%$ greater risk of COVID-19 death. However, evidence of non-linearity was observed in the analysis of BMI and risk of COVID-19 death, with a J-shaped dose-response relation with flattening of the dose-response curve between 22 and 24 of BMI level and a slight increase below that range and a 1.5-2-fold increase in risk with a BMI of 40-45. While there was no publication bias, study heterogeneity was high for all exposure and this persisted in most of the subgroup analyses. However, the heterogeneity appeared to be driven to a larger extent by differences in the strength of the associations, than differences in the direction of the effect, as the vast majority of studies reported significant or non-significant positive associations between these exposures and increased mortality, and relatively few studies reported risk estimates in the direction of an inverse association. Given this meta-analysis included more studies than a typical meta-analysis, $\mathrm{I}^{2}$ and heterogeneity were high as the likelihood of divergent findings increases with increasing number of studies.

\section{Comparisons to findings from previous epidemiological studies and biological mechanisms}

Since the first reports of COVID-19, several studies have shown that patients with COVID-19 with comorbidities have a higher risk of death. ${ }^{417244245}$ However, these studies 
have differed greatly in term of sample size, and results are conflicting and heterogeneous. Previous meta-analyses have shown that patients with diabetes, hypertension and obesity had an increased risk of mortality. ${ }^{16-18} 21246247$ Unfortunately, these previous meta-analyses were limited by the lack of subgroup analyses, which is crucial to evaluate heterogeneity and no previous meta-analysis has estimated the number of deaths attributed to these comorbidities or conditions.

This meta-analysis summarises the results of 186 observational studies published up to November 2020, including 210447 deaths among 1304587 million patients with COVID-19. Our findings are similar to results from previously published systematic reviews, suggesting a higher mortality rate of COVID-19 in patients with cardiovascular or chronic condition. ${ }^{161721} 22$ We found a 1.54-fold greater mortality from COVID-19 among patient with diabetes compared with those without ( $\mathrm{n}=145$ studies), which is similar to those yielded in previous meta-analyses, ${ }^{16}$ whereas the estimate magnitude is weaker than those in de Almeida-Pititto et al, ${ }^{21}$ Kumar et $a l,{ }^{246}$ Shang et $a l^{248}$ and Luo et al. ${ }^{17}$ In our subgroup analyses, we found that the positive association was stronger in studies without any adjustment or adjusted for age only compared with studies that adjusted for multiple factors. Thus, the higher magnitude observed in the previous metaanalyses may be in part due to the important number of studies without adjustment for confounding factors such as age and comorbidities, which are mostly with critical or serious risk of bias. In addition, we estimated that $8 \%$ of deaths by COVID- 19 were attributed to diabetes; this aspect has to our knowledge not been investigated previously. The absolute risk of death associated with diabetes was increased by $14 \%$. The mechanism underlying the increased mortality from COVID-19 in patients with diabetes may be explained by chronic inflammatory conditions. Patients with COVID-19 with diabetes have a significantly higher inflammatory markers such as $\mathrm{C}$ reactive protein (CRP), interleukin 6 (IL-6) compared with patients without diabetes. ${ }^{249}$ Inflammatory markers such as IL-6, CRP, IL-10, lactate dehydrogenase and tumor necrosis factor- $\alpha$, which are indicative of different aspects of COVID-19 severity, requirements of intensive care support including dialysis and ventilation, are associated with higher risk of death. ${ }^{250} 251$

Regarding hypertension, our findings yielded a 1.42fold higher risk of death from COVID-19 in patient with hypertension ( $\mathrm{n}=127$ studies), which also is slightly weaker than the results from previous meta-analyses. ${ }^{16} 22247$ Nearly $7 \%$ of death in patients with COVID-19 could be attributed to hypertension and we found that hypertension increased the absolute risk of death by $11 \%$. Previous clinical studies showed that hypertension is a major risk factor for worse outcome in patients infected with SARS and Middle East respiratory syndrome. ${ }^{252} 253$ Although, the exact mechanism by which hypertension increase mortality rate remains unclear, chronic inflammation may play an active role in increasing risk of death.
Du et al suggested that patients with obesity had a 2.68-fold risk for COVID-19 mortality compared with non-obese patients ( $\mathrm{n}=7$ studies). ${ }^{18}$ In dose-response analysis, they showed that for each $1 \mathrm{~kg} / \mathrm{m}^{2}$ increase in BMI, the risk of death increased by $6 \%$. Partly consistent with this study, we found that a $5 \mathrm{~kg} / \mathrm{m}^{2}$ increase in BMI level was associated with a $12 \%$ increase in the risk of death in patient with COVID-19 ( $\mathrm{n}=25$ studies). In addition, we found evidence of a non-linear J-shaped association between BMI and mortality from COVID-19, with a flattening of the dose-response curve for BMI values between 22 and $24 \mathrm{~kg} / \mathrm{m}^{2}$ and with a slightly higher risk below that range and a moderate to strong increase in mortality with severe obesity (BMI 40-45). Obesity is associated with a low-grade systemic inflammation, which plays a major role in the pathogenesis of respiratory conditions. Patients with COVID-19 and with preexisting obesity may have an overactivated inflammation response, which may induce excessive inflammatory response. ${ }^{254}$ Obesity is also strongly associated with increased risk of diabetes, hypertension and several other chronic diseases ${ }^{255}$ that increases risk of COVID-19 mortality. ${ }^{256}$

In addition, our finding showed that ever, current and former smoking was associated with $28 \%, 29 \%$ and $25 \%$ increases in the relative risk of death in patients with COVID-19 compared with never smokers. Tobacco smoking is known to alter the function of the immune system; therefore smokers are more likely to get a severe infection of COVID-19 due to their poor mucociliary clearance, which could lead to the release of proinflammatory markers and oxidative stress and thereby contribute to higher mortality rates. The risk of death in former smokers was higher than in never smokers and only slightly lower than risk in current smoker. However, more studies are required to clarify the impact of longer durations of smoking cessation in former smokers on risk of death in patients with COVID-19.

Although we found that diabetes, hypertension, BMI and smoking were associated with greater COVID-19 mortality, a recent meta-analysis suggested that mortality was more frequently observed in patients with COVID-19 with cardiovascular disease, cerebrovascular accident and chronic kidney disease. ${ }^{257}$ The authors observed that COVID-19 mortality among all comorbidities was high in European and Latin American patients compared with the US patients. It is possible that geographical differences in therapeutic practice of COVID-19 such as the use of antibiotics, antivirals and others drugs may partly explain the greater COVID-19 death in some regions, ${ }^{258}$ while there was no evidence of heterogeneity in findings across geographic location in our study. The review also suggested that COVID-19 mortality among those with underlying medical diseases was high in mostly elderly patients. ${ }^{258}$ However, we did not perform subgroup analysis by age because this information was lacking in most of the included studies. 


\section{Strengths, limitations and public health implications}

This present meta-analysis of observational studies on diabetes, hypertension, obesity and smoking and risk of death in patients with COVID-19 has several strengths, including the large sample size and number of COVID-19 deaths, the detailed subgroup and sensitivity analyses, as well as the linear and non-linear dose-response analyses, which clarified the strength and shape of the doseresponse relationship. Original aspects of our study included the estimation of the number of deaths attributable to these conditions. This is, to our knowledge, the first meta-analysis that perform a separate analysis of ever, current and former smoking versus never smoking in relation to COVID-19 mortality. As any previous published meta-analyses, the current analysis has some limitations that should be considered in the interpretation of our findings. First, we did not investigate the association between presence of two or more coexisting comorbidities and risk of death in patients with COVID-19. Finally, subgroup analyses stratified by clinical or lifestyle factors such as medications, diabetes type and duration, adherence to specific diet, or physical activity were not possible because of the lack of such data from the studies included.

Despite these limitations, our findings may have important public health implications in the context of increasing numbers of severe COVID-19 cases, overburdened hospitals and leading to higher hospital death due to COVID-19 and suggest that people with cardiovascular risk factors, in particular those with diabetes, hypertension and obesity, should be considered as a high priority to get vaccinated. In addition, since smoking is a risk factor for several chronic diseases, including cancer and cardiovascular disease, our finding lend support to the importance of smoking prevention and smoking cessation and support policies and public health efforts to reduce the prevalence smoking in the general population.

\section{CONCLUSION}

Our finding suggests that presence of diabetes, hypertension, obesity and smoking in patients with COVID-19 is associated with a 1.54-fold, 1.42-fold, 1.45-fold and 1.28fold greater risk of mortality, respectively. We have found that the proportion of death attributable to diabetes, hypertension, obesity and smoking was $8 \%, 7 \%, 11 \%$ and $2 \%$, respectively. These findings support that people with diabetes, hypertension, obesity should be prioritised for vaccination in order to limit the higher death rates in hospital. Public policies should promote a healthier lifestyle including healthier diets and regular physical activity to reduce patient risk factors and comorbidities.

\footnotetext{
Author affiliations

${ }^{1}$ Paris-Saclay University, UVSQ, Inserm, Gustave Roussy, "Exposome and Heredity" team, CESP, F-94805, Villejuif, France

${ }^{2}$ Department of Plant Molecular Biology, Faculty of Biology and Medicine, University of Lausanne, Lausanne, Switzerland

${ }^{3}$ Laboratory of Soil Biodiversity, Faculty of Science, University of Neuchatel, Neuchâtel, Switzerland
}

${ }^{4}$ Universite de Paris, IAME, INSERM, Paris, France

${ }^{5}$ National Institute for Health Research, Health Protection Research Unit in Healthcare Associated Infections and Antimicrobial Resistance, Imperial College London, London, UK

${ }^{6}$ Infectious and Tropical Diseases Department, Bichat-Claude Bernard Hospital, AP-HP, Paris, France

${ }^{7}$ Department of Epidemiology and Biostatistics, School of Public Health, Imperial College London, London, UK

${ }^{8}$ Department of Nutrition, Bjørknes University College, Oslo, Norway

${ }^{9}$ Department of Endocrinology, Morbid Obesity and Preventive Medicine, Oslo University Hospital, 0slo, Norway

${ }^{10}$ Unit of Cardiovascular and Nutritional Epidemiology, Institute of Environmental Medicine, Karolinska Institutet, Stockholm, Sweden

${ }^{11}$ Department of Statistics, Computer Science and Applications "G. Parenti", University of Florence, Florence, Italy

Twitter Yahya Mahamat-Saleh @MS_Yahya_,Thibault Fiolet @T_Fiolet, Mathieu Edouard Rebeaud @Damkyan_Omega and Anthony Guihur @AnthonyGuihur

Contributors YM-S conceived and designed the research. YM-S performed statistical analysis and wrote the first draft of the paper. YM-S, TF and MER performed the literature search and literature screening. YM-S and TF assessed the risk of bias of the studies and assessed the certainty of evidence of the associations. MM assisted with the statistical analysis. YM-S, TF, MER, MM, AG, DEF, NL, NP-S, DA and GS contributed to data interpretation and revision of the manuscript for intellectual content. YM-S takes responsibility for the integrity of the data and the accuracy of the data analysis. YM-S is responsible for the overall content as guarantor.

Funding The authors have not declared a specific grant for this research from any funding agency in the public, commercial or not-for-profit sectors.

Competing interests None declared.

Patient consent for publication Not applicable.

Provenance and peer review Not commissioned; externally peer reviewed.

Data availability statement All data relevant to the study are included in the article or uploaded as supplementary information.

Supplemental material This content has been supplied by the author(s). It has not been vetted by BMJ Publishing Group Limited (BMJ) and may not have been peer-reviewed. Any opinions or recommendations discussed are solely those of the author(s) and are not endorsed by BMJ. BMJ disclaims all liability and responsibility arising from any reliance placed on the content. Where the content includes any translated material, BMJ does not warrant the accuracy and reliability of the translations (including but not limited to local regulations, clinical guidelines, terminology, drug names and drug dosages), and is not responsible for any error and/or omissions arising from translation and adaptation or otherwise.

Open access This is an open access article distributed in accordance with the Creative Commons Attribution Non Commercial (CC BY-NC 4.0) license, which permits others to distribute, remix, adapt, build upon this work non-commercially, and license their derivative works on different terms, provided the original work is properly cited, appropriate credit is given, any changes made indicated, and the use is non-commercial. See: http://creativecommons.org/licenses/by-nc/4.0/.

\section{ORCID iDs}

Yahya Mahamat-Saleh http://orcid.org/0000-0002-5892-8886

Anthony Guihur http://orcid.org/0000-0001-5353-1428

Dagfinn Aune http://orcid.org/0000-0002-4533-1722

\section{REFERENCES}

1 Zhu N, Zhang D, Wang W, et al. A novel coronavirus from patients with pneumonia in China, 2019. N Engl J Med Overseas Ed 2020;382:727-33.

2 WHO. Coronavirus disease (COVID-19) pandemic, 2020. Available: https://www.who.int/emergencies/diseases/novel-coronavirus2019? gclid=CjwKCAiA57D_BRAZEiwAZcfCxWRma5FQmvw6WgYE sv692kL7rMdTuLqwaaSN7-HfqOrjcu-rrfGYpBoCT1IQAvD_BwE

3 World Health Organization (WHO). Who coronavirus disease (COVID-19) Dashboard. Available: https://covid19.who.int/?gclid= CjwKCAiA57D_BRAZEiwAZcfCxWQWth4sNaEZ1J34KInDRNOj iLuwzkFwpDNCU7V2CPqCPGDU2jLYfhoCb6UQAvD_BwE 
4 Zhou F, Yu T, Du R, et al. Clinical course and risk factors for mortality of adult inpatients with COVID-19 in Wuhan, China: a retrospective cohort study. Lancet 2020;395:1054-62.

5 Onder G, Rezza G, Brusaferro S. Case-Fatality rate and characteristics of patients dying in relation to COVID-19 in Italy. JAMA 2020;323:1775-1776.

6 Goldstein JR, Lee RD. Demographic perspectives on the mortality of COVID-19 and other epidemics. Proc Natl Acad Sci U S A 2020;117:22035-41.

7 Demombynes G. COVID-19 age-mortality curves are flatter in developing countries 2020

8 Richardson S, Hirsch JS, Narasimhan M, et al. Presenting characteristics, comorbidities, and outcomes among 5700 patients hospitalized with COVID-19 in the new York City area. JAMA 2020;323:2052-9.

9 Wang D, Hu B, Hu C, et al. Clinical characteristics of 138 hospitalized patients with 2019 novel coronavirus-infected pneumonia in Wuhan, China. JAMA 2020;323:1061.

10 Huang C, Wang Y, Li X, et al. Clinical features of patients infected with 2019 novel coronavirus in Wuhan, China. The Lancet 2020;395:497-506.

11 Yang J, Zheng Y, Gou X, et al. Prevalence of comorbidities and its effects in patients infected with SARS-CoV-2: a systematic review and meta-analysis. Int J Infect Dis 2020;94:91-5.

12 Siordia JA. Epidemiology and clinical features of COVID-19: a review of current literature. J Clin Virol 2020;127:104357.

13 Guan W-J, Liang W-H, Zhao Y, et al. Comorbidity and its impact on 1590 patients with COVID-19 in China: a nationwide analysis. Eur Respir J 2020;55:2000547.

14 Khan MMA, Khan MN, Mustagir MG, et al. Effects of underlying morbidities on the occurrence of deaths in COVID-19 patients: a systematic review and meta-analysis. $J$ Glob Health 2020;10:020503.

15 Liu K, Fang Y-Y, Deng Y, et al. Clinical characteristics of novel coronavirus cases in tertiary hospitals in Hubei Province. Chin Med J 2020;133:1025-31.

16 Ssentongo P, Ssentongo AE, Heilbrunn ES, et al. Association of cardiovascular disease and 10 other pre-existing comorbidities with COVID-19 mortality: a systematic review and meta-analysis. PLoS One 2020;15:e0238215.

17 Luo L, Fu M, Li Y, et al. The potential association between common comorbidities and severity and mortality of coronavirus disease 2019: a pooled analysis. Clin Cardiol 2020;43:1478-93.

18 Du Y, Lv Y, Zha W, et al. Association of body mass index (BMI) with critical COVID-19 and in-hospital mortality: a dose-response metaanalysis. Metabolism 2021:117:154373.

19 Karanasos A, Aznaouridis K, Latsios G, et al. Impact of smoking status on disease severity and mortality of hospitalized patients with COVID-19 infection: a systematic review and meta-analysis. Nicotine Tob Res 2020;22:1657-9.

20 Hussain A, Mahawar K, Xia Z, et al. Obesity and mortality of COVID-19. meta-analysis. Obes Res Clin Pract 2020;14:295-300.

21 de Almeida-Pititto B, Dualib PM, Zajdenverg L, et al. Severity and mortality of COVID 19 in patients with diabetes, hypertension and cardiovascular disease: a meta-analysis. Diabetol Metab Syndr 2020;12:75

22 Noor FM, Islam MM. Prevalence and associated risk factors of mortality among COVID-19 patients: a meta-analysis. J Community Health 2020;45:1270-82.

23 Chu Y, Yang J, Shi J, et al. Obesity is associated with increased severity of disease in COVID-19 pneumonia: a systematic review and meta-analysis. Eur J Med Res 2020;25:64.

24 Popkin BM, Du S, Green WD, et al. Individuals with obesity and COVID-19: a global perspective on the epidemiology and biological relationships. Obes Rev 2020;21:e13128.

25 Seidu S, Gillies C, Zaccardi F, et al. The impact of obesity on severe disease and mortality in people with SARS-CoV-2: a systematic review and meta-analysis. Endocrinol Diabetes Metab 2020:e00176.

26 Mesas AE, Cavero-Redondo I, Álvarez-Bueno C, et al. Predictors of in-hospital COVID-19 mortality: a comprehensive systematic review and meta-analysis exploring differences by age, sex and health conditions. PLoS One 2020;15:e0241742.

27 Alqahtani JS, Oyelade T, Aldhahir AM, et al. Prevalence, severity and mortality associated with COPD and smoking in patients with COVID-19: a rapid systematic review and meta-analysis. PLoS One 2020;15:e0233147.

28 Neumann-Podczaska A, Chojnicki M, Karbowski LM, et al. Clinical characteristics and survival analysis in a small sample of older COVID-19 patients with defined 60-Day outcome. Int J Environ Res Public Health 2020;17:8362.
29 Gutierrez JP, Bertozzi SM. Non-Communicable diseases and inequalities increase risk of death among COVID-19 patients in Mexico. PLoS One 2020;15:e0240394.

30 Albitar O, Ballouze R, Ooi JP, et al. Risk factors for mortality among COVID-19 patients. Diabetes Res Clin Pract 2020;166:108293.

31 Al-Salameh A, Lanoix J-P, Bennis Y, et al. Characteristics and outcomes of COVID-19 in hospitalized patients with and without diabetes. Diabetes Metab Res Rev 2021;37:e3388.

32 Hashemi N, Viveiros K, Redd WD, et al. Impact of chronic liver disease on outcomes of hospitalized patients with COVID-19: a multicentre United States experience. Liver Int 2020;40:2515-21.

33 Atkins JL, Masoli JAH, Delgado J, et al. Preexisting comorbidities predicting COVID-19 and mortality in the UK Biobank community cohort. J Gerontol A Biol Sci Med Sci 2020;75:2224-30.

34 Barron E, Bakhai C, Kar P, et al. Associations of type 1 and type 2 diabetes with COVID-19-related mortality in England: a wholepopulation study. Lancet Diabetes Endocrinol 2020;8:813-22.

35 Barbu MG, Thompson RJ, Thompson DC, et al. The impact of SARS-CoV-2 on the most common Comorbidities-A retrospective study on 814 COVID-19 deaths in Romania. Front Med 2020;7:567199.

36 Boulle A, Davies M-A, Hussey H, et al. Risk factors for coronavirus disease 2019 (COVID-19) death in a population cohort study from the Western Cape Province, South Africa. Clin Infect Dis 2021;73:e2005-15.

37 Bousquet G, Falgarone G, Deutsch D, et al. ADL-dependency, $\mathrm{D}$-dimers, LDH and absence of anticoagulation are independently associated with one-month mortality in older inpatients with Covid-19. Aging 2020;12:11306-13.

38 Calmes D, Graff S, Maes N, et al. Asthma and COPD are not risk factors for ICU stay and death in case of SARS-CoV2 infection. $J$ Allergy Clin Immunol Pract 2021;9:160-169.

39 Carrasco-Sánchez FJ, López-Carmona Mª Dolores, MartínezMarcos FJ, et al. Admission hyperglycaemia as a predictor of mortality in patients hospitalized with COVID-19 regardless of diabetes status: data from the Spanish SEMI-COVID-19 registry. Ann Med 2021;53:103-16.

40 Chachkhiani D, Soliman MY, Barua D, et al. Neurological complications in a predominantly African American sample of COVID-19 predict worse outcomes during hospitalization. Clin Neurol Neurosurg 2020:197:106173.

41 Chang MC, Hwang J-M, Jeon J-H, et al. Fasting plasma glucose level independently predicts the mortality of patients with coronavirus disease 2019 infection: a multicenter, retrospective cohort study. Endocrinol Metab 2020;35:595-601.

42 Chilimuri S, Sun H, Alemam A, et al. Predictors of mortality in adults admitted with COVID-19: retrospective cohort study from New York City. West J Emerg Med 2020;21:779-84.

43 Ciardullo S, Zerbini F, Perra S, et al. Impact of diabetes on COVID19-related in-hospital mortality: a retrospective study from northern Italy. J Endocrinol Invest 2021;44:843-50.

44 pp Coppelli A, Giannarelli R, Aragona M, et al. Hyperglycemia at hospital admission is associated with severity of the prognosis in patients hospitalized for COVID-19: the Pisa COVID-19 study. Diabetes Care 2020;43:2345-8.

45 Crouse A, Grimes T, Li P, et al. Metformin use is associated with reduced mortality in a diverse population with COVID-19 and diabetes. medRxiv 2020. doi:10.1101/2020.07.29.20164020. [Epub ahead of print: $31 \mathrm{Jul} 2020]$.

46 Dennis JM, Mateen BA, Sonabend R, et al. Type 2 diabetes and COVID-19-Related mortality in the critical care setting: a national cohort study in England, March-July 2020. Diabetes Care 2021;44:50-7.

47 Desai A, Voza G, Paiardi S, et al. The role of anti-hypertensive treatment, comorbidities and early introduction of LMWH in the setting of COVID-19: a retrospective, observational study in northern Italy. Int J Cardiol 2021;324:249-54.

48 de Souza Silva GA, da Silva SP, da Costa MAS, et al. Sars-Cov, MERS-CoV and SARS-CoV-2 infections in pregnancy and fetal development. J Gynecol Obstet Hum Reprod 2020;101846:101846.

49 Escalera-Antezana JP, Lizon-Ferrufino NF, Maldonado-Alanoca A, et al. Risk factors for mortality in patients with coronavirus disease 2019 (COVID-19) in Bolivia: an analysis of the first 107 confirmed cases. Infez Med 2020;28:238-42.

50 Esme M, Koca M, Dikmeer A, et al. Older adults with coronavirus disease 2019: a nationwide study in turkey. J Gerontol A Biol Sci Med Sci 2021;76:e68-75

51 Fernández-Cruz A, Ruiz-Antorán B, Muñoz-Gómez A, et al. A retrospective controlled cohort study of the impact of glucocorticoid treatment in SARS-CoV-2 infection mortality. Antimicrob Agents Chemother 2020;64:e01168-20. 
52 Fried MW, Crawford JM, Mospan AR, et al. Patient characteristics and outcomes of 11721 patients with coronavirus disease 2019 (COVID-19) hospitalized across the United States. Clin Infect Dis 2021;72:e558-65.

53 Galloway JB, Norton S, Barker RD, et al. A clinical risk score to identify patients with COVID-19 at high risk of critical care admission or death: an observational cohort study. J Infect 2020;81:282-8.

54 Ghany R, Palacio A, Chen G. Prior cardiovascular risk and screening echocardiograms predict hospitalization and severity of coronavirus infection among elderly Medicare patients. AmJPrevCardiol 2020;3:100090.

55 Guisado-Vasco P, Valderas-Ortega S, Carralón-González MM, et al. Clinical characteristics and outcomes among hospitalized adults with severe COVID-19 admitted to a tertiary medical center and receiving antiviral, antimalarials, glucocorticoids, or immunomodulation with tocilizumab or cyclosporine: a retrospective observational study (COQUIMA cohort). EClinicalMedicine 2020;28:100591.

56 Haase N, Plovsing R, Christensen S, et al. Characteristics, interventions, and longer term outcomes of COVID-19 ICU patients in Denmark-A nationwide, observational study. Acta Anaesthesiol Scand 2021;65:68-75.

57 Harrison SL, Fazio-Eynullayeva E, Lane DA, et al. Comorbidities associated with mortality in 31,461 adults with COVID-19 in the United States: a federated electronic medical record analysis. PLoS Med 2020;17:e1003321.

58 Narain S, Stefanov DG, Chau AS, et al. Comparative surviva analysis of immunomodulatory therapy for coronavirus disease 2019 cytokine storm. Chest 2021;159:933-48.

59 laccarino G, Grassi G, Borghi C, et al. Age and multimorbidity predict death among COVID-19 patients: results of the SARSRAS study of the Italian Society of hypertension. Hypertension 2020;76:366-72.

60 Lampasona V, Secchi M, Scavini M, et al. Antibody response to multiple antigens of SARS-CoV-2 in patients with diabetes: an observational cohort study. Diabetologia 2020;63:2548-58.

61 pp Lombardi CM, Carubelli V, lorio A, et al. Association of troponin levels with mortality in Italian patients hospitalized with coronavirus disease 2019: results of a multicenter study. JAMA Cardiol 2020;5:1274-7.

62 Lunski MJ, Burton J, Tawagi K, et al. Multivariate mortality analyses in COVID-19: comparing patients with cancer and patients without cancer in Louisiana. Cancer 2021:127:266-74.

63 Maddaloni E, D'Onofrio L, Alessandri F. Cardiometabolic multimorbidity is associated with a worse Covid-19 prognosis than individual cardiometabolic risk factors: a multicentre retrospective study (CoViDiab II). CardiovascDiabetol 2020;19:164.

64 Mallow PJ, Belk KW, Topmiller M, et al. Outcomes of hospitalized COVID-19 patients by risk factors: results from a United States Hospital claims database. $J$ Health Econ Outcomes Res 2020;7:165-75.

65 McCarty TR, Hathorn KE, Redd WD. How do presenting symptoms and outcomes differ by Race/Ethnicity among hospitalized patients with coronavirus disease 2019 infection? experience in Massachusetts. Clinical Infectious Diseases 2020;69:458-64.

66 McCullough SA, Goyal P, Krishnan U, et al. Electrocardiographic findings in coronavirus Disease-19: insights on mortality and underlying myocardial processes. J Card Fail 2020;26:626-32.

67 Mendy A, Apewokin S, Wells AA. Factors associated with hospitalization and disease severity in a racially and ethnically diverse population of COVID-19 patients. medRxiv 2020.

68 Soares RdeCM, Mattos LR, Raposo LM. Risk factors for hospitalization and mortality due to COVID-19 in Espírito Santo state, Brazil. Am J Trop Med Hyg 2020;103:1184-90.

69 Mirani M, Favacchio G, Carrone F. Impact of Comorbidities and Glycemia at Admission and Dipeptidyl Peptidase 4 Inhibitors in Patients With Type 2 Diabetes With COVID-19: A Case Series From an Academic Hospital in Lombardy, Italy. Diabetes care(no pagination 2020;06

70 Moon SJ, Rhee E-J, Jung J-H, et al. Independent impact of diabetes on the severity of coronavirus disease 2019 in 5,307 patients in South Korea: a nationwide cohort study. Diabetes Metab J 2020;44:737-46.

71 Moon SS, Lee K, Park J, et al. Clinical characteristics and mortality predictors of COVID-19 patients hospitalized at NationallyDesignated treatment hospitals. J Korean Med Sci 2020;35:e328.

72 Munblit D, Nekliudov NA, Bugaeva P, et al. Stop COVID cohort: an observational study of 3480 patients admitted to the Sechenov university hospital network in Moscow City for suspected coronavirus disease 2019 (COVID-19) infection. Clin Infect Dis 2021;73:1-11.

73 Nachega JB, Ishoso DK, Otokoye JO, et al. Clinical characteristics and outcomes of patients hospitalized for COVID-19 in Africa: early insights from the Democratic Republic of the Congo. Am J Trop Med Hyg 2020;103:2419-28.

74 Nakeshbandi M, Maini R, Daniel P, et al. The impact of obesity on COVID-19 complications: a retrospective cohort study. Int J Obes 2020;44:1832-7.

75 Anzola GP, Bartolaminelli C, Gregorini GA, et al. Neither ACEls nor Arbs are associated with respiratory distress or mortality in COVID-19 results of a prospective study on a hospital-based cohort. Intern Emerg Med 2020;15:1477-84.

76 Nicholson CJ, Wooster L, Sigurslid HH. Estimating risk of mechanical ventilation and mortality among adult COVID-19 patients admitted to mass General Brigham: the vice and dice scores. medRxiv2020.

77 Nogueira PJ, de Araújo Nobre M, Costa A, et al. The role of health preconditions on COVID-19 deaths in Portugal: evidence from surveillance data of the first 20293 infection cases. J Clin Med 2020;9:2368.

78 Pan W, Zhang J, Wang M, et al. Clinical features of COVID-19 in patients with essential hypertension and the impacts of reninangiotensin-aldosterone system inhibitors on the prognosis of COVID-19 patients. Hypertension 2020;76:732-41.

79 Portolés J, Marques M, López-Sánchez P, et al. Chronic kidney disease and acute kidney injury in the COVID-19 Spanish outbreak. Nephrol Dial Transplant 2020;35:1353-61.

80 Rastad H, Karim H, Ejtahed H-S, et al. Risk and predictors of in-hospital mortality from COVID-19 in patients with diabetes and cardiovascular disease. Diabetol Metab Syndr 2020;12:57.

81 Recinella G, Marasco G, Serafini G, et al. Prognostic role of nutritional status in elderly patients hospitalized for COVID-19: a monocentric study. Aging Clin Exp Res 2020;32:2695-701.

82 Reilev M, Kristensen KB, Pottegård A, et al. Characteristics and predictors of hospitalization and death in the first 11122 cases with a positive RT-PCR test for SARS-CoV-2 in Denmark: a nationwide cohort. Int J Epidemiol 2020;49:1468-81.

83 Rivera-Izquierdo M, Del Carmen Valero-Ubierna M, R-delAmo $\mathrm{JL}$, et al. Sociodemographic, clinical and laboratory factors on admission associated with COVID-19 mortality in hospitalized patients: a retrospective observational study. PLoS One 2020;15:e0235107.

84 Rodríguez-Molinero A, Gálvez-Barrón C, Miñarro A, et al. Association between COVID-19 prognosis and disease presentation, comorbidities and chronic treatment of hospitalized patients. PLoS One 2020;15:e0239571.

85 Giorgi Rossi P, Marino M, Formisano D, et al. Characteristics and outcomes of a cohort of COVID-19 patients in the province of Reggio Emilia, Italy. PLoS One 2020;15:e0238281.

$86 \mathrm{pp}$ Rottoli M, Bernante P, Belvedere A, et al. How important is obesity as a risk factor for respiratory failure, intensive care admission and death in hospitalised COVID-19 patients? results from a single Italian centre. Eur J Endocrinol 2020;183:389-97.

87 Rozaliyani A, Savitri Al, Setianingrum F, et al. Factors associated with death in COVID-19 patients in Jakarta, Indonesia: an epidemiological study. Acta Med Indones 2020;52:246-54

88 Salacup G, Lo KB, Gul F, et al. Characteristics and clinical outcomes of COVID-19 patients in an underserved-inner City population: a single tertiary center cohort. J Med Virol 2021;93:416-23.

89 Salazar E, Christensen PA, Graviss EA, et al. Treatment of coronavirus disease 2019 patients with convalescent plasma reveals a signal of significantly decreased mortality. Am J Pathol 2020;190:2290-303.

90 Sands KE, Wenzel RP, McLean LE, et al. Patient characteristics and admitting vital signs associated with coronavirus disease 2019 (COVID-19)-related mortality among patients admitted with noncritical illness. Infect Control Hosp Epidemiol 2021;42:399-405.

91 Santos MM, Lucena EES, Lima KC, et al. Survival and predictors of deaths of patients hospitalised due to COVID-19 from a retrospective and multicentre cohort study in Brazil. Epidemiol Infect 2020;148: 198 .

92 Seiglie J, Platt J, Cromer SJ, et al. Diabetes as a risk factor for poor early outcomes in patients hospitalized with COVID-19. Diabetes Care 2020;43:2938-44

93 Shah P, Owens J, Franklin J, et al. Demographics, comorbidities and outcomes in hospitalized Covid-19 patients in rural Southwest Georgia. Ann Med 2020;52:354-60.

$94 \mathrm{Li}$ P, Chen L, Liu Z, et al. Clinical features and short-term outcomes of elderly patients with COVID-19. Int J Infect Dis 2020;97:245-50. 
95 Shang J, Wang Q, Zhang $\mathrm{H}$, et al. The relationship between diabetes mellitus and COVID-19 prognosis: a retrospective cohort study in Wuhan, China. Am J Med 2021;134:e6-14.

96 Smith AA, Fridling J, Ibrahim D, et al. Identifying patients at greatest risk of mortality due to COVID-19: a new England perspective. West J Emerg Med 2020;21:785-9.

97 Tartof SY, Qian L, Hong V, et al. Obesity and mortality among patients diagnosed with COVID-19: results from an integrated health care organization. Ann Intern Med 2020;173:773-81.

98 Turcotte JJ, Meisenberg BR, MacDonald JH, et al. Risk factors for severe illness in hospitalized Covid-19 patients at a regional hospital. PLoS One 2020;15:e0237558.

99 Wollenstein-Betech S, Silva AAB, Fleck JL, et al. Physiological and socioeconomic characteristics predict COVID-19 mortality and resource utilization in Brazil. PLoS One 2020;15:e0240346.

100 Yahyavi A, Hemmati N, Derakhshan P, et al. Angiotensin enzyme inhibitors and angiotensin receptor blockers as protective factors in COVID-19 mortality: a retrospective cohort study. Intern Emerg Med 2021;16:883-93.

101 Yan Y, Yang Y, Wang F, et al. Clinical characteristics and outcomes of patients with severe covid-19 with diabetes. BMJ Open Diabetes Res Care 2020;8:e001343.

102 Yan Q, Zuo P, Cheng L, et al. Acute kidney injury is associated with in-hospital mortality in older patients with COVID-19. J Gerontol A Biol Sci Med Sci 2021;76:456-62.

103 Yazdanpanah Y, French COVID cohort investigators and study group. Impact on disease mortality of clinical, biological, and virological characteristics at hospital admission and overtime in COVID-19 patients. J Med Virol 2021;93:2149-59.

104 Zandkarimi E, Moradi G, Mohsenpour B. The prognostic factors affecting the survival of Kurdistan Province COVID-19 patients: a cross-sectional study from February to may 2020. Int $\mathrm{J}$ Health Policy Manag 2020. doi:10.34172/ijhpm.2020.155. [Epub ahead of print: 22 Aug 2020]

105 An C, Lim H, Kim D-W, et al. Machine learning prediction for mortality of patients diagnosed with COVID-19: a nationwide Korean cohort study. Sci Rep 2020;10:18716.

$106 \mathrm{pp} \mathrm{Bepouka} \mathrm{BI,} \mathrm{Mandina} \mathrm{M,} \mathrm{Makulo} \mathrm{JR,} \mathrm{et} \mathrm{al.} \mathrm{Predictors} \mathrm{of}$ mortality in COVID-19 patients at Kinshasa university Hospital, Democratic Republic of the Congo (from March to June 2020). Pan Afr Med J 2020;37:1105-17.

107 Abohamr SI, Abazid RM, Aldossari MA, et al. Clinical characteristics and in-hospital mortality of COVID-19 adult patients in Saudi Arabia. Saudi Med J 2020;41:1217-26.

108 Czernichow S, Beeker N, Rives-Lange C, et al. Obesity doubles mortality in patients hospitalized for severe acute respiratory syndrome coronavirus 2 in Paris hospitals, France: a cohort study on 5,795 patients. Obesity 2020;28:2282-9.

109 Harmouch F, Shah K, Hippen JT, et al. Is it all in the heart? myocardial injury as major predictor of mortality among hospitalized COVID-19 patients. J Med Virol 2021;93:973-82.

110 Hewitt J, Carter B, Vilches-Moraga A, et al. The effect of frailty on survival in patients with COVID-19 (cope): a multicentre, European, observational cohort study. Lancet Public Health 2020;5:e444-51.

111 loannou GN, Locke E, Green P, et al. Risk Factors for Hospitalization, Mechanical Ventilation, or Death Among 10131 US Veterans With SARS-CoV-2 Infection. JAMA Netw Open 2020;3:e2022310.

112 Kabarriti R, Brodin NP, Maron Ml, et al. Association of race and ethnicity with comorbidities and survival among patients with COVID-19 at an urban medical center in New York. JAMA Netw Open 2020;3:e2019795.

113 Kolhe NV, Fluck RJ, Selby NM, et al. Acute kidney injury associated with COVID-19: a retrospective cohort study. PLoS Med 2020;17:e1003406.

114 Meng Y, Lu W, Guo E, et al. Cancer history is an independent risk factor for mortality in hospitalized COVID-19 patients: a propensity score-matched analysis. J Hematol Oncol 2020;13:75

115 Ñamendys-Silva SA, Alvarado-Ávila PE, Domínguez-Cherit G, et al. Outcomes of patients with COVID-19 in the intensive care unit in Mexico: a multicenter observational study. Heart Lung 2021;50:28-32.

$116 \mathrm{Li} \mathrm{G}$, Deng Q, Feng J, et al. Clinical characteristics of diabetic patients with COVID-19. J Diabetes Res 2020;2020:1652403.

117 Nie S-F, Yu M, Xie T, et al. Cardiac troponin I is an independent predictor for mortality in hospitalized patients with COVID-19. Circulation 2020;142:608-10.

118 Núñez-Gil IJ, Fernández-Pérez C, Estrada V, et al. Mortality risk assessment in Spain and Italy, insights of the hope COVID-19 registry. Intern Emerg Med 2021;16:957-66.
119 Park JG, Kang MK, Lee YR, et al. Fibrosis-4 index as a predictor for mortality in hospitalised patients with COVID-19: a retrospective multicentre cohort study. BMJ Open 2020;10:e041989.

120 Parker WH. Bilateral oophorectomy versus ovarian conservation: effects on long-term women's health. J Minim Invasive Gynecol 2010;17:161-6.

121 Rosenberg ES, Dufort EM, Udo T, et al. Association of treatment with hydroxychloroquine or azithromycin with in-hospital mortality in patients with COVID-19 in New York state. JAMA 2020;323:2493-502.

122 Tehrani S, Killander A, Åstrand P, et al. Risk factors for death in adult COVID-19 patients: frailty predicts fatal outcome in older patients. Int J Infect Dis 2021;102:415-21.

123 Moher D, Liberati A, Tetzlaff $\mathrm{J}$, et al. Preferred reporting items for systematic reviews and meta-analyses: the PRISMA statement. BMJ 2009;339:b2535.

124 Stroup DF, Berlin JA, Morton SC, et al. Meta-Analysis of observational studies in epidemiology: a proposal for reporting. meta-analysis of observational studies in epidemiology (moose) group. JAMA 2000;283:2008-12.

125 Sterne JA, Hernán MA, Reeves BC, et al. ROBINS-I: a tool for assessing risk of bias in non-randomised studies of interventions. BMJ 2016;355:i4919.

126 Schünemann HJ, Cuello C, Akl EA, et al. Grade guidelines: 18. How ROBINS-I and other tools to assess risk of bias in nonrandomized studies should be used to rate the certainty of a body of evidence. $J$ Clin Epidemiol 2019;111:105-14.

127 DerSimonian R, Laird N. Meta-Analysis in clinical trials. Control Clin Trials 1986;7:177-88.

128 Higgins JPT, Thompson SG. Quantifying heterogeneity in a metaanalysis. Stat Med 2002;21:1539-58.

129 Docherty AB, Harrison EM, Green CA, et al. Features of 20133 UK patients in hospital with covid-19 using the ISARIC WHO Clinical Characterisation Protocol: prospective observational cohort study. BMJ 2020;369:m1985.

130 Newcombe RG, Bender R. Implementing grade: calculating the risk difference from the baseline risk and the relative risk. Evid Based Med 2014;19:6-8.

131 Greenland S, Longnecker MP. Methods for trend estimation from summarized dose-response data, with applications to metaanalysis. Am J Epidemiol 1992;135:1301-9.

132 Hamling J, Lee P, Weitkunat R, et al. Facilitating meta-analyses by deriving relative effect and precision estimates for alternative comparisons from a set of estimates presented by exposure level or disease category. Stat Med 2008;27:954-70.

133 Bagnardi V, Zambon A, Quatto P, et al. Flexible meta-regression functions for modeling aggregate dose-response data, with an application to alcohol and mortality. Am J Epidemiol 2004:159:1077-86.

134 Egger M, Davey Smith G, Schneider M, et al. Bias in meta-analysis detected by a simple, graphical test. BMJ 1997;315:629-34.

135 Spiegelman D, Hertzmark E, Wand HC. Point and interval estimates of partial population attributable risks in cohort studies: examples and software. Cancer Causes Control 2007:18:571-9.

136 Moazzami B, Chaichian S, Kasaeian A, et al. Metabolic risk factors and risk of Covid-19: a systematic review and meta-analysis. PLOS One 2020:15:e0243600.

137 Farsalinos K, Barbouni A, Poulas K, et al. Current smoking, former smoking, and adverse outcome among hospitalized COVID-19 patients: a systematic review and meta-analysis. Ther Adv Chronic Dis 2020;11:2040622320935765.

138 Shastri MD, Shukla SD, Chong WC, et al. Smoking and COVID-19: what we know so far. Respir Med 2021;176:106237.

139 Acharya D, Lee K, Lee DS, et al. Mortality rate and predictors of mortality in hospitalized COVID-19 patients with diabetes. Health Care 2020;8:338.

140 Jackson BR, Gold JAW, Natarajan P, et al. Predictors at admission of mechanical ventilation and death in an observational cohort of adults hospitalized with COVID-19. Clin Infect Dis 2020:ciaa1459.

141 Braude P, Carter B, Short R, et al. The influence of ACE inhibitors and Arbs on hospital length of stay and survival in people with COVID-19. Int J Cardiol Heart Vasc 2020;31:100660.

142 Cai Y, Shi S, Yang F, et al. Fasting blood glucose level is a predictor of mortality in patients with COVID-19 independent of diabetes history. Diabetes Res Clin Pract 2020;169:108437.

143 Hwang J-M, Kim J-H, Park J-S, et al. Neurological diseases as mortality predictive factors for patients with COVID-19: a retrospective cohort study. Neurol Sci 2020;41:2317-24.

144 Williamson EJ, Walker AJ, Bhaskaran K, et al. Factors associated with COVID-19-related death using OpenSAFELY. Nature 2020:584:430-6. 
145 Bruce E, Barlow-Pay F, Short R, et al. Prior routine use of non-steroidal anti-inflammatory drugs (NSAIDs) and important outcomes in hospitalised patients with covid-19. J Clin Med 2020;9:2586.

146 Carrillo-Vega MF, Salinas-Escudero G, García-Peña C, et al. Early estimation of the risk factors for hospitalization and mortality by COVID-19 in Mexico. PLoS One 2020;15:e0238905.

147 Hernández-Galdamez DR, González-Block Miguel Ángel, RomoDueñas DK, et al. Increased Risk of Hospitalization and Death in Patients with COVID-19 and Pre-existing Noncommunicable Diseases and Modifiable Risk Factors in Mexico. Arch Med Res 2020;51:683-9.

148 Parra-Bracamonte GM, Lopez-Villalobos N, Parra-Bracamonte FE. Clinical characteristics and risk factors for mortality of patients with COVID-19 in a large data set from Mexico. Ann Epidemiol 2020;52:93-8

149 Wollenstein-Betech S, Cassandras CG, Paschalidis IC. Personalized predictive models for symptomatic COVID-19 patients using basic preconditions: hospitalizations, mortality, and the need for an ICU or ventilator. Int J Med Inform 2020;142:104258.

150 Hernández-Vásquez A, Azañedo D, Vargas-Fernández R, et al. Association of comorbidities with pneumonia and death among COVID-19 patients in Mexico: a nationwide cross-sectional study. $J$ Prev Med Public Health 2020;53:211-9.

151 Shi S, Qin M, Shen B, et al. Association of cardiac injury with mortality in hospitalized patients with COVID-19 in Wuhan, China. JAMA Cardiol 2020;5:802-10.

152 Mehra MR, Desai SS, Kuy S, et al. Cardiovascular disease, drug therapy, and mortality in COVID-19. N Engl J Med Overseas Ed 2020;382:e102.

153 Cao Y, Han X, Gu J, et al. Prognostic value of baseline clinical and HRCT findings in 101 patients with severe COVID-19 in Wuhan, China. Sci Rep 2020;10:16.

154 Di Castelnuovo A, Bonaccio M, Costanzo S, et al. Common cardiovascular risk factors and in-hospital mortality in 3,894 patients with COVID-19: survival analysis and machine learningbased findings from the multicentre Italian CORIST study. Nutr Metab Cardiovasc Dis 2020;30:1899-913.

155 Chen Y, Yang D, Cheng B, et al. Clinical characteristics and outcomes of patients with diabetes and COVID-19 in association with glucose-lowering medication. Diabetes Care 2020;43:1399-407.

156 Chen F, Sun W, Sun S, et al. Clinical characteristics and risk factors for mortality among inpatients with COVID-19 in Wuhan, China. Clin Transl Med 2020;10:e40.

157 Cummings MJ, Baldwin MR, Abrams D, et al. Epidemiology, clinical course, and outcomes of critically ill adults with COVID-19 in New York City: a prospective cohort study. The Lancet 2020;395:1763-70.

158 Fang $\mathrm{H}$, Liu Q, Xi M, et al. Impact of comorbidities on clinical prognosis in 1280 patients with different types of COVID-19. J Investig Med 2021;69:75-85.

159 Grasselli G, Greco M, Zanella A, et al. Risk factors associated with mortality among patients with COVID-19 in intensive care units in Lombardy, Italy. JAMA Intern Med 2020;180:1345-55.

$160 \mathrm{Gu}$ T, Chu Q, Yu Z, et al. History of coronary heart disease increased the mortality rate of patients with COVID-19: a nested case-control study. BMJ Open 2020;10:e038976

161 Gu T, Mack JA, Salvatore M, et al. COVID-19 outcomes, risk factors and associations by race: a comprehensive analysis using electronic health records data in Michigan medicine. medRxiv 2020 doi:10.1101/2020.06.16.20133140. [Epub ahead of print: 18 Jun 2020].

162 Gupta S, Hayek SS, Wang W, et al. Factors associated with death in critically ill patients with coronavirus disease 2019 in the US. JAMA Intern Med 2020;180:1436-47.

$163 \mathrm{Hu}$ W, Dong M, Xiong M, et al. Clinical courses and outcomes of patients with chronic obstructive pulmonary disease during the COVID-19 epidemic in Hubei, China. Int J Chron Obstruct Pulmon Dis 2020;15:2237-48.

164 Imam Z, Odish F, Gill I, et al. Older age and comorbidity are independent mortality predictors in a large cohort of 1305 COVID-19 patients in Michigan, United States. J Intern Med 2020;288:469-76.

$165 \mathrm{Kim}$ DW, Byeon KH, Kim J, et al. The correlation of comorbidities on the mortality in patients with COVID-19: an observational study based on the Korean National health insurance big data. $J$ Korean Med Sci 2020;35:e243.

166 Klang E, Soffer S, Nadkarni G, et al. Sex differences in age and comorbidities for COVID-19 mortality in urban New York City. SN Compr Clin Med 2020:1319-22.
167 Kim L, Garg S, O'Halloran A, et al. Risk Factors for Intensive Care Unit Admission and In-hospital Mortality Among Hospitalized Adults Identified through the US Coronavirus Disease 2019 (COVID-19)Associated Hospitalization Surveillance Network (COVID-NET). Clin Infect Dis 2021;72:e206-14.

$168 \mathrm{Li} \mathrm{H}$, Tian S, Chen T, et al. Newly diagnosed diabetes is associated with a higher risk of mortality than known diabetes in hospitalized patients with COVID-19. Diabetes Obes Metab 2020;22:1897-906.

169 Lee JY, Kim HA, Huh K, et al. Risk factors for mortality and respiratory support in elderly patients hospitalized with COVID-19 in Korea. J Korean Med Sci 2020;35:e223.

170 Li L, Li F, Fortunati F, et al. Association of a prior psychiatric diagnosis with mortality among hospitalized patients with coronavirus disease 2019 (COVID-19) infection. JAMA Netw Open 2020;3:e2023282

171 Lui GC-Y, Yip TC-F, Wong VW-S, et al. Significantly lower casefatality ratio of coronavirus disease 2019 (COVID-19) than severe acute respiratory syndrome (SARS) in Hong Kong -A Territory-Wide cohort study. Clin Infect Dis 2021;72:e466-75.

172 Liu J, Zhang S, Wu Z, et al. Clinical outcomes of COVID-19 in Wuhan, China: a large cohort study. Ann Intensive Care 2020;10:99.

173 Liu Z, Li J, Huang J, et al. Association between diabetes and COVID-19: a retrospective observational study with a large sample of 1,880 cases in Leishenshan Hospital, Wuhan. Front Endocrinol 2020;11:478.

174 Mikami T, Miyashita H, Yamada T, et al. Risk factors for mortality in patients with COVID-19 in New York City. J Gen Intern Med 2021;36:17-26.

175 Palaiodimos L, Chamorro-Pareja N, Karamanis D, et al. Diabetes is associated with increased risk for in-hospital mortality in patients with COVID-19: a systematic review and meta-analysis comprising 18,506 patients. Hormones 2021;20:305-14.

176 Perkin MR, Heap S, Crerar-Gilbert A, et al. Deaths in people from black, Asian and minority ethnic communities from both COVID-19 and non-COVID causes in the first weeks of the pandemic in London: a hospital case note review. BMJ Open 2020;10:e040638.

177 Petrilli CM, Jones SA, Yang J, et al. Factors associated with hospital admission and critical illness among 5279 people with coronavirus disease 2019 in New York City: prospective cohort study. BMJ 2020;369:m1966.

178 Pettit NN, MacKenzie EL, Ridgway JP, et al. Obesity is associated with increased risk for mortality among hospitalized patients with COVID-19. Obesity 2020;28:1806-10.

179 Poblador-Plou B, Carmona-Pírez J, loakeim-Skoufa I, et al. Baseline chronic comorbidity and mortality in Laboratory-Confirmed COVID-19 cases: results from the PRECOVID study in Spain. Int $J$ Environ Res Public Health 2020;17:5171.

180 Shi Q, Zhang X, Jiang F, et al. Clinical characteristics and risk factors for mortality of COVID-19 patients with diabetes in Wuhan, China: a two-center, retrospective study. Diabetes Care 2020:43:1382-91.

181 Sousa GJB, Garces TS, Cestari VRF, et al. Mortality and survival of COVID-19. Epidemiol Infect 2020;148:e123.

182 Stony Brook COVID-19 Research Consortium. Geospatial distribution and predictors of mortality in hospitalized patients with COVID-19: a cohort study. Open Forum Infect Dis 2020;7:ofaa436.

183 Talavera B, García-Azorín D, Martínez-Pías E, et al. Anosmia is associated with lower in-hospital mortality in COVID-19. J Neurol Sci 2020:419:117163.

184 Xie J, Zu Y, Alkhatib A, et al. Metabolic syndrome and COVID-19 mortality among adult black patients in New Orleans. Diabetes Care 2020. doi:10.2337/dc20-1714. [Epub ahead of print: 25 Aug 2020].

185 Wu C, Chen X, Cai Y, et al. Risk factors associated with acute respiratory distress syndrome and death in patients with coronavirus disease 2019 pneumonia in Wuhan, China. JAMA Intern Med 2020;180:934-43.

$186 \mathrm{Wu}$ J, Huang J, Zhu G, et al. Elevation of blood glucose level predicts worse outcomes in hospitalized patients with COVID-19: a retrospective cohort study. BMJ Open Diabetes Res Care 2020;8:e001476.

187 Yang P, Wang N, Wang J, et al. Admission fasting plasma glucose is an independent risk factor for 28-day mortality in patients with COVID-19. J Med Virol 2021;93:2168-76.

188 Yu C, Lei Q, Li W, et al. Clinical characteristics, associated factors, and predicting COVID-19 mortality risk: a retrospective study in Wuhan, China. Am J Prev Med 2020;59:168-75.

189 Zhang J, Kong W, Xia P, et al. Impaired fasting glucose and diabetes are related to higher risks of complications and mortality among patients with coronavirus disease 2019. Front Endocrinol 2020;11:525. 
190 Zhu L, She Z-G, Cheng X, et al. Association of blood glucose control and outcomes in patients with COVID-19 and pre-existing type 2 diabetes. Cell Metab 2020;31:1068-77.

191 Zimering MB, Razzaki T, Tsang T, et al. Inverse association between serotonin $2 \mathrm{~A}$ receptor antagonist medication use and mortality in severe COVID-19 infection. Endocrinol Diabetes Metab J 2020;4:1-5.

192 Almazeedi S, Al-Youha S, Jamal MH, et al. Characteristics, risk factors and outcomes among the first consecutive 1096 patients diagnosed with COVID-19 in Kuwait. EClinicalMedicine 2020;24:100448.

193 Foy BH, Carlson JCT, Reinertsen E, et al. Association of red blood cell distribution width with mortality risk in hospitalized adults with SARS-CoV-2 infection. JAMA Netw Open 2020;3:e2022058.

194 Shi S, Qin M, Cai Y, et al. Characteristics and clinical significance of myocardial injury in patients with severe coronavirus disease 2019. Eur Heart J 2020;41:2070-9.

195 Wang F, Cao J, Yu Y, et al. Epidemiological characteristics of patients with severe COVID-19 infection in Wuhan, China: evidence from a retrospective observational study. Int J Epidemiol 2021;49:1940-50

196 Arshad S, Kilgore P, Chaudhry ZS, et al. Treatment with hydroxychloroquine, azithromycin, and combination in patients hospitalized with COVID-19. Int J Infect Dis 2020;97:396-403.

197 Berenguer J, Ryan P, Rodríguez-Baño J, et al. Characteristics and predictors of death among 4035 consecutively hospitalized patients with COVID-19 in Spain. Clin Microbiol Infect 2020;26:1525-36.

198 Ciceri F, Castagna A, Rovere-Querini P, et al. Early predictors of clinical outcomes of COVID-19 outbreak in Milan, Italy. Clin Immunol 2020;217:108509.

199 Deng G, Yin M, Chen X, et al. Clinical determinants for fatality of 44,672 patients with COVID-19. Crit Care 2020;24:179.

200 Wang K, Zuo P, Liu Y, et al. Clinical and laboratory predictors of inhospital mortality in 305 patients with COVID-19: a cohort study in Wuhan, China. SSRN Journal 2020.

201 Biscarini S, Colaneri M, Ludovisi S, et al. The obesity paradox: analysis from the SMAtteo COvid-19 registry (SMACORE) cohort. Nutr Metab Cardiovasc Dis 2020;30:1920-5.

202 Biscarini S, Colaneri M, Ludovisi S, et al. The obesity paradox: analysis from the SMAtteo COvid-19 registry (SMACORE) cohort. Nutr Metab Cardiovasc Dis 2020;30:30.

203 CA D, Costanzo S, Antinori A, et al. Raas inhibitors are not associated with mortality in COVID-19 patients: findings from an observational multicenter study in Italy and a meta-analysis of 19 studies. Vascul Pharmacol 2020;135:106805.

204 De Vito A, Geremia N, Fiore V, et al. Clinical features, laboratory findings and predictors of death in hospitalized patients with COVID-19 in Sardinia, Italy. Eur Rev Med Pharmacol Sci 2020;24:7861-8.

205 Gao C, Cai Y, Zhang K, et al. Association of hypertension and antihypertensive treatment with COVID-19 mortality: a retrospective observational study. Eur Heart J 2020;41:2058-66.

206 Giacomelli A, Ridolfo AL, Milazzo L, et al. 30-Day mortality in patients hospitalized with COVID-19 during the first wave of the Italian epidemic: a prospective cohort study. Pharmacol Res 2020;158:104931

207 Liu J, Liu Z, Jiang W, et al. Clinical predictors of COVID-19 disease progression and death: analysis of 214 hospitalised patients from Wuhan, China. Clin Respir J 2021;15:293-309.

208 Liu D, Wang Y, Wang J, et al. Characteristics and outcomes of a sample of patients with COVID-19 identified through social media in Wuhan, China: observational study. $\mathrm{J}$ Med Internet Res 2020;22:e20108.

209 Magleby R, Westblade LF, Trzebucki A, et al. Impact of SARSCoV-2 viral load on risk of intubation and mortality among hospitalized patients with coronavirus disease 2019. Clin Infect Dis 2020;30:ciaa851.

210 Matsuzawa Y, Ogawa H, Kimura K, et al. Renin-Angiotensin system inhibitors and the severity of coronavirus disease 2019 in Kanagawa, Japan: a retrospective cohort study. Hypertens Res 2020;43:1257-66

211 Muñoz P, Galar A, Catalán P, et al. The first 100 cases of COVID-19 in a hospital in Madrid with a 2-month follow-up. Rev Esp Quimioter 2020;33:369-78.

212 Russo E, Esposito P, Taramasso L, et al. Kidney disease and allcause mortality in patients with COVID-19 hospitalized in Genoa, Northern Italy. J Nephrol 2021;34:173-83.

213 Zangrillo A, Beretta L, Scandroglio AM. Characteristics, treatment, outcomes and cause of death of invasively ventilated patients with COVID-19 ARDS in Milan, Italy. Crit Care Resusc 2020. [Epub ahead of print: 23 Apr 2020].
214 Almazeedi S, Al-Youha S, Jamal MH, et al. Characteristics, risk factors and outcomes among the first consecutive 1096 patients diagnosed with COVID-19 in Kuwait. EClinicalMedicine 2020;24:100448.

215 Brouns SH, Brüggemann R, Linkens AEMJH, et al. Mortality and the use of antithrombotic therapies among nursing home residents with COVID-19. J Am Geriatr Soc 2020;68:1647-52.

216 Lopez-Mendez I, Aquino-Matus J, Gall SM-B, et al. Association of liver steatosis and fibrosis with clinical outcomes in patients with SARS-CoV-2 infection (COVID-19). Ann Hepatol 2021;20:100271.

217 Du R-H, Liang L-R, Yang C-Q, et al. Predictors of mortality for patients with COVID-19 pneumonia caused by SARS-CoV-2: a prospective cohort study. Eur Respir J 2020;55:2000524

218 Mowla SGM, Azad KAK, Kabir A, et al. Clinical profile of 100 confirmed COVID-19 patients admitted in Dhaka medical college Hospital, Dhaka, Bangladesh. Journal of Bangladesh College of Physicians and Surgeons 2020:29-36.

219 Sun H, Ning R, Tao Y, et al. Risk factors for mortality in 244 older adults with COVID-19 in Wuhan, China: a retrospective study. J Am Geriatr Soc 2020;68:E19-23.

220 Alamdari NM, Afaghi S, Rahimi FS, et al. Mortality risk factors among hospitalized COVID-19 patients in a major referral center in Iran. Tohoku J Exp Med 2020;252:73-84.

221 Hajifathalian K, Kumar S, Newberry C, et al. Obesity is associated with worse outcomes in COVID-19: analysis of early data from New York City. Obesity 2020;28:1606-12.

222 Klang E, Kassim G, Soffer S, et al. Severe obesity as an independent risk factor for COVID-19 mortality in hospitalized patients younger than 50 . Obesity 2020;28:1595-9.

223 Price-Haywood EG, Burton J, Fort D, et al. Hospitalization and mortality among black patients and white patients with Covid-19. N Engl J Med 2020;382:2534-43.

224 Ramos-Rincon J-M, Buonaiuto V, Ricci M, et al. Clinical characteristics and risk factors for mortality in very old patients hospitalized with COVID-19 in Spain. J Gerontol A Biol Sci Med Sci 2021;76:e28-37.

225 Steinberg E, Wright E, Kushner B. In young adults with COVID-19, obesity is associated with adverse outcomes. West $\mathrm{J}$ Emerg Med 2020;21:752-5.

226 Zhang F, Xiong Y, Wei Y, et al. Obesity predisposes to the risk of higher mortality in young COVID-19 patients. J Med Virol 2020;92:2536-42.

227 Gazzaruso C, Mariani G, Ravetto C, et al. Lupus anticoagulant and mortality in patients hospitalized for COVID-19. J Thromb Thrombolysis 2021;52:85-91.

228 Mather JF, Seip RL, McKay RG. Impact of famotidine use on clinical outcomes of hospitalized patients with COVID-19. Am J Gastroenterol 2020;115:1617-23.

229 Anderson MR, Geleris J, Anderson DR, et al. Body Mass Index and Risk for Intubation or Death in SARS-CoV-2 Infection : A Retrospective Cohort Study. Ann Intern Med 2020;173:782-90.

230 Ferrando-Vivas P, Doidge J, Thomas K, et al. Prognostic factors for 30-day mortality in critically ill patients with coronavirus disease 2019: an observational cohort study. Crit Care Med 2021:49:102-11.

231 Gayam V, Chobufo MD, Merghani MA, et al. Clinical characteristics and predictors of mortality in African-Americans with COVID-19 from an inner-city community teaching hospital in New York. $J$ Med Virol 2021;93:812-9.

232 Muñoz-Price LS, Nattinger AB, Rivera F, et al. Racial disparities in incidence and outcomes among patients with COVID-19. JAMA Netw Open 2020;3:e2021892.

233 Li G, Zhou C-L, Ba Y-M, et al. Nutritional risk and therapy for severe and critical COVID-19 patients: a multicenter retrospective observational study. Clin Nutr 2021;40:2154-61.

234 Wang Z, Zheutlin A, Kao Y-H, et al. Hospitalised COVID-19 patients of the Mount Sinai health system: a retrospective observational study using the electronic medical records. BMJ Open 2020;10:e040441.

235 Baronio M, Freni-Sterrantino A, Pinelli M, et al. Italian SARS-CoV-2 patients in intensive care: towards an identikit for subjects at risk? Eur Rev Med Pharmacol Sci 2020;24:9698-704.

236 Adrish M, Chilimuri S, Mantri N, et al. Association of smoking status with outcomes in hospitalised patients with COVID-19. BMJ Open Respir Res 2020;7:e000716.

237 Chen L, Yu J, He W, et al. Risk factors for death in 1859 subjects with COVID-19. Leukemia 2020;34:2173-83.

238 Zhang J-J, Cao Y-Y, Tan G, et al. Clinical, radiological, and laboratory characteristics and risk factors for severity and mortality of 289 hospitalized COVID-19 patients. Allergy 2021:76:533-50. 
239 Alharthy A, Aletreby W, Faqihi F, et al. Clinical characteristics and predictors of 28-day mortality in 352 critically ill patients with COVID-19: a retrospective study. J Epidemiol Glob Health 2021;11:98.

240 Qin L, Li X, Shi J, et al. Gendered effects on inflammation reaction and outcome of COVID-19 patients in Wuhan. J Med Virol 2020;92:2684-92.

241 Wang Z-H, Shu C, Ran X, et al. Critically ill patients with coronavirus disease 2019 in a designated ICU: clinical features and predictors for mortality. Risk Manag Healthc Policy 2020;13:833-45.

242 Farrell RJ, O'Regan R, O'Neill E, et al. Sociodemographic variables as predictors of adverse outcome in SARS-CoV-2 infection: an Irish Hospital experience. Ir J Med Sci 2021;190:893-903.

243 Wang K, Zuo P, Liu Y, et al. Clinical and laboratory predictors of in-hospital mortality in patients with coronavirus Disease-2019: a cohort study in Wuhan, China. Clin Infect Dis 2020;71:2079-88.

244 Chen T, Dai Z, Mo P, et al. Clinical characteristics and outcomes of older patients with coronavirus disease 2019 (COVID-19) in Wuhan, China: a Single-Centered, retrospective study. J Gerontol A Biol Sci Med Sci 2020;75:1788-95

245 Yang X, Yu Y, Xu J, et al. Clinical course and outcomes of critically ill patients with SARS-CoV-2 pneumonia in Wuhan, China: a singlecentered, retrospective, observational study. Lancet Respir Med 2020;8:475-81.

246 Kumar A, Arora A, Sharma P, et al. Is diabetes mellitus associated with mortality and severity of COVID-19? A meta-analysis. Diabetes Metab Syndr 2020;14:535-45.

247 Pranata R, Huang I, Lim MA, et al. Impact of cerebrovascular and cardiovascular diseases on mortality and severity of COVID-19systematic review, meta-analysis, and meta-regression. J Stroke Cerebrovasc Dis 2020;29:104949.

248 Shang L, Shao M, Guo Q, et al. Diabetes mellitus is associated with severe infection and mortality in patients with COVID-19: a systematic review and meta-analysis. Arch Med Res 2020;51:700-9
249 Varikasuvu SR, Varshney S, Dutt N. Markers of coagulation dysfunction and inflammation in diabetic and non-diabetic COVID-19. J Thromb Thrombolysis 2021;51:941-6.

250 Maddaloni E, Buzzetti R. Covid-19 and diabetes mellitus: unveiling the interaction of two pandemics. Diabetes Metab Res Rev 2020:e33213321.

251 Kermali M, Khalsa RK, Pillai K, et al. The role of biomarkers in diagnosis of COVID-19 - A systematic review. Life Sci 2020;254:117788.

252 Morra ME, Van Thanh L, Kamel MG, et al. Clinical outcomes of current medical approaches for middle East respiratory syndrome: a systematic review and meta-analysis. Rev Med Virol 2018;28:e1977.

253 Matsuyama R, Nishiura H, Kutsuna S, et al. Clinical determinants of the severity of middle East respiratory syndrome (MERS): a systematic review and meta-analysis. BMC Public Health 2016;16:1203.

254 Yang J, Hu J, Zhu C. Obesity aggravates COVID-19: a systematic review and meta-analysis. J Med Virol 2021;93:257-61.

255 Guh DP, Zhang W, Bansback N, et al. The incidence of comorbidities related to obesity and overweight: a systematic review and meta-analysis. BMC Public Health 2009;9:88.

256 Semenzato L, Botton J, Drouin J, et al. Chronic diseases, health conditions and risk of COVID-19-related hospitalization and in-hospital mortality during the first wave of the epidemic in France: a cohort study of 66 million people. Lancet Reg Health Eur 2021;8:100158

257 Thakur B, Dubey P, Benitez J, et al. A systematic review and metaanalysis of geographic differences in comorbidities and associated severity and mortality among individuals with COVID-19. Sci Rep 2021;11:8562.

258 Dubey P, Thakur B, Reddy S, et al. Current trends and geographical differences in therapeutic profile and outcomes of COVID-19 among pregnant women - a systematic review and meta-analysis. BMC Pregnancy Childbirth 2021;21:247. 